\title{
INDUSTRIA DE CONTENIDOS AUDIOVISUALES \\ Y PLATAFORMAS DIGITALES: ANÁLISIS DESDE EL DERECHO \\ DE LA COMPETENCIA
}

THE AUDIOVISUAL CONTENT INDUSTRY AND DIGITAL PLATFORMS: AN ANALYSIS FROM THE PERSPECTIVE OF ANTITRUST LAW

\author{
Pablo Márquez* \\ Márquez Barrera Castañeda \& Ramírez Consultores \\ María Fernanda Arciniegas ${ }^{* *}$ \\ Departamento Nacional de Planeación de Colombia
}

\begin{abstract}
Recent technological developments have led to important changes in the competition dynamics of the audiovisual content industry. The digitalization and easier access to the internet have increased the supply and demand of these types of products. The entry of new economic agents and new production and distribution methods must force us to reconsider the applicable antitrust policy for this industry.
\end{abstract}

In light of this, this paper proposes we focus the analysis on the competition between suppliers for the consumers' attention. Consequently, the authors explore the definition of relevant market in the audiovisual content industry and digital platforms traditionally welcomed by Latin-American, European and American regulatory bodies and competition agencies (with a special emphasis on the acquisition of 21st Century Fox by Disney), as well as analyze the way these work and the possible obstacles to free competition inside them.

KEYWORDS: Audiovisual content; digital platforms; streaming; free competition; Superintendencia de Industria y Comercio.
El avance tecnológico de los últimos años ha producido importantes cambios en las dinámicas competitivas de la industria de contenidos audiovisuales. La digitalización y la mayor facilidad en el acceso a Internet ha incrementado la oferta y demanda dentro de este sector. El ingreso de nuevos agentes al mercado y de nuevos modos de producción y distribución de contenido nos obliga a repensar la normativa de competencia aplicable a esta industria.

Ante ello, los autores proponen enfocar el análisis en la competencia entre los agentes de este mercado por captar y cautivar la atención de los consumidores. Con este objetivo, exploran las definiciones de mercado relevante en la industria de contenidos audiovisuales y plataformas digitales que tradicionalmente han acogido los organismos reguladores y las agencias de competencia latinoamericanas, europeas y estadounidense (con un especial énfasis en la reciente adquisición de 21st Century Fox por Disney), y analizan el funcionamiento y los posibles obstáculos a la libre competencia dentro de ellos.

Palabras Clave: Contenidos audiovisuales; plataformas digitales; streaming; libre competencia; Superintendencia de Industria y Comercio.

\footnotetext{
* Abogado y filósofo. Magíster en Economía por la Pontificia Universidad Javeriana de Bogotá, Master of Laws (LL.M.) por la Harvard Law School y doctor en Derecho de la Competencia (Ph.D.) por la University of Oxford. Ex Director Ejecutivo de la Comisión de Regulación de Comunicaciones de Colombia (CRC) y ex Superintendente Delegado para la Protección de la Competencia en la Superintendencia de Industria y Comercio de Colombia (SIC). Socio fundador de Márquez Barrera Castañeda \& Ramírez Consultores (Bogotá, Colombia). Contacto: pablo@marquezbarrera.com

** Abogada. Master en Política Pública (M.P.P.) por la University of Oxford. Ex Asesora de Política Pública en la Unidad Contra la Manipulación en Internet del Department for Digital, Culture, Media \& Sport (DCMS) del Reino Unido y ex asociada sénior en Márquez Barrera Castañeda \& Ramírez Consultores. Asesora del Grupo de Modernización del Estado del Departamento Nacional de Planeación (Bogotá, Colombia). Contacto: mfarciniegas89@gmail.com
}

El presente artículo fue recibido por el Consejo Ejecutivo de THËMIS-Revista de Derecho el 2 de julio de 2020, y aceptado por el mismo el 22 de octubre de 2020. 


\section{INTRODUCCIÓN: LA ECONOMÍA CREATIVA, LA ECONOMÍA DIGITAL Y LA ECONOMÍA DE LA ATENCIÓN}

La economía creativa, en Colombia conocida como la economía naranja, comprende una amplia gama de sectores en los cuales el valor de los bienes y servicios se calcula sobre la base de la propiedad intelectual relacionada con la creación de estos, abarcando productos creativos que van desde la publicidad hasta la tecnología educativa, los videojuegos, la ópera, la moda, el cine y otros (Buitrago Restrepo \& Duque Márquez, 2013). Así, la economía naranja convierte los frutos de la propiedad intelectual y la experiencia imaginativa en productos, enmarcados en la intersección que se presenta entre el diseño, la tecnología, la ingeniería, las experiencias y la expresión.

Un sector de la literatura define a esta industria como "aquellas actividades que tienen su origen en la creatividad, la habilidad y el talento individual, y que tienen el potencial de crear empleos y riqueza a través de la generación y la explotación de la propiedad intelectual" (BOP Consulting, 2010, p. 14). De acuerdo con un estudio de Oxford Economics, las industrias creativas representan un potencial económico subestimado, y tienen la capacidad de realizar una contribución positiva a la economía de la innovación y a otros sectores de la economía (2014).

Más aún, dichas industrias reflejan una promesa significativa, ya que la data muestra que este sector representa una proporción creciente del PIB nacional en países como Argentina, Brasil, Colombia, Paraguay y los Estados Unidos (Oxford Economics, 2014). Asimismo, las variables de consumo e infraestructura creativas, como el aumento en el número de teatros y cines, y el incremento en el número de profesionales de software y contenido digital, al igual que el aumento en el patrón de consumo para videojuegos, publicidad y películas, proporcionan un contexto positivo para su desarrollo futuro (2014).

De hecho, las industrias creativas y culturales constituyen uno de los sectores de más rápido crecimiento a nivel global (2014). Según la Conferencia de Naciones Unidas para el Comercio y el DesarroIlo (UNCTAD por sus siglas en inglés), entre 2002 y 2011 las exportaciones de bienes y servicios creativos crecieron un 134\% (Buitrago Restrepo \& Duque Márquez, 2013). En atención a esta dinámica, el Banco Interamericano de Desarrollo ha determinado que, si los países de América Latina buscan alcanzar una economía creativa y de alto crecimiento, es vital que se protejan los negocios en este sector (Oxford Economics, 2014). Ante ese contexto, se destaca la necesidad de desarrollar marcos estadísticos y regulatorios comunes para respaldar la formulación de políticas basadas en evidencias que permitan al sector continuar prosperando, para que así contribuya al crecimiento, el empleo y el desarrollo (Oxford Economics, 2014).

En adición, en el espectro de la economía creativa ha de tenerse en cuenta un elemento esencial: el Internet, ya que esta innovación disruptiva (Morales Montejo, 2014) cumple un rol fundamental en razón de que ha facilitado la comunicación y el manejo de la información, por lo que se erige como un componente indispensable en el éxito de la economía creativa (Oxford Economics, 2014). No debe desconocerse que estamos en la era de la abundancia informativa, pues gracias a los desarrollos tecnológicos innovadores y al Internet hay cada vez más personas creando y compartiendo contenido creativo, con perspectivas más amplias y diversas.

El Internet ha incrementado la dinámica competitiva de los mercados, ya que ha facilitado la entrada de nuevos competidores y, por ende, ha permitido una mayor variedad de productos y servicios ofrecidos. Frente a la importancia de la Internet, debe resaltarse el que hoy en día cada vez más son los agentes de mercado que compiten por la atención de los consumidores, lo que ha llevado a que este elemento se vuelva un recurso valioso y limitado.

Los mercados de atención se han modelado con base en la presencia de dos grupos de actores (emisores y receptores/audiencias), en donde los primeros envían señales costosas encaminadas a captar la atención de los segundos y generar un impacto en éstos, partiendo de la premisa de que los receptores cuentan con una capacidad de atención limitada, por razones de tiempo o cognitivas (Falkinger, 2003). Las señales -o en el caso de mercados audiovisuales, los contenidos - contarán con una capacidad de radiación particular, que determina la dimensión máxima de audiencia que puede ser alcanzada (Falkinger, 2003); como se verá más adelante, en el caso de contenidos ofrecidos por medio de Internet, las barreras geográficas y demográficas se difuminan en cierta medida dado el amplio alcance de esta red global. Sin embargo, cabe señalar que estas no se eliminan por completo, a causa de que existen divergencias en la cobertura geográfica de las licencias otorgadas a distribuidores de contenido.

La literatura económica no ha ignorado este problema. Ello se puede ver en lo que expresaba Hotelling, en 1938:

Another thing of limited quantity for which the demand exceeds the supply is the attention of people. Attention is desired for a variety of 
commercial, political, and other purposes, and is obtained with the help of billboards, newspaper, radio, and other advertising. Expropriation of the attention of the general public and its commercial sale and exploitation constitute a lucrative business. From some aspects, this business appears to be of a similar character to that of the medieval robber barons, and therefore to be an appropriate subject for prohibition by a state democratically controlled by those from whom their attention is stolen (p. 257) ${ }^{1}$.

De tal forma, la atención como producto, así como un eventual mercado de atención, se ha vuelto tan dinámica y competida al punto de que la atención misma ha sido erradamente considerada como una moneda o valor de cambio (Teixeira, 2014). Lo anterior ha significado un cambio en la aproximación a algunos de los mercados más importantes y disruptivos de la actualidad, en tanto que los modelos de negocio no se sustentan sobre la base de la venta de productos, sino en la atracción de la atención de los consumidores (Wu, 2017).

Efectivamente, al describir el funcionamiento de los mercados digitales, Batura et al. destacan cómo los efectos de la red presentes en dichos mercados conducen a que, independientemente del modelo de negocio empleado, el éxito de muchas empresas digitales dependa de su capacidad de atraer la atención de los usuarios finales (2015). Esto es, compiten entre ellas por una audiencia, empleando una estrategia competitiva y de mercadeo en la que, en ocasiones, resulta más rentable permitir a oferentes minoristas o anunciantes publicitarios el acceso a sus audiencias, que cobrar un precio directo -entendido como valor pecuniario- a dichos usuarios (Batura et al. 2015). Como complemento de lo anterior, cabría mencionar la siguiente conclusión a la que arriba el Conseil supérieur de l'audiovisuel (CSA) francés en su estudio "Plataformas y Acceso a Contenido Audiovisual":

Since the priority of all media is to keep its audience in its environment for as long as possible in order to draw as much value as they can from it (in-depth knowledge of users, exposure to advertising, etc.), more traditional platforms and audiovisual players compete directly to attract visitors and are consequently direct competitors on the advertising market (2016, p. 45) [el énfasis es nuestro]².

Así, en cuanto a las industrias creativas que proveen contenido que es susceptible de atraer la atención, se puede pensar en productos ofrecidos por animadores, arquitectos, directores de arte, especialistas en impresión tridimensional, especialistas en branding, directores creativos, diseñadores de moda, cineastas, agentes de viajes, desarrolladores de juegos, diseñadores gráficos, diseñadores industriales, diseñadores de iluminación, tecnólogos de medios, músicos, tecnólogos de museos, fotógrafos, proyección de mapeo de artistas, escultores, diseñadores de sonido, técnicos de teatro, tecnólogos de realidad virtual, escritores y editores de guías turísticas (Evans, 2013, p. 330).

Todos estos productores de contenido, finalmente, compiten por la atención de los consumidores (2013, p. 317). Insistimos que se entiende por atención a la cantidad limitada de tiempo asignada para procesar la información. En el sector del entretenimiento, esta puede verse como el tiempo de visualización o viewing time (Budzinski \& LinstädtDreusicke, 2018). Dado que el tiempo es limitado y el contenido de las industrias creativas es básicamente ilimitado, los consumidores deben tomar la decisión de qué productos consumir (o ignorar) y a cuáles prestarles atención. Esta ponderación variará según la edad de la audiencia: por ejemplo, los jóvenes suelen tener mayor tiempo libre que la población adulta trabajadora, divergencia que se acentúa cuando esta tiene compromisos familiares (Budzinski \& Linstädt-Dreusicke, 2018, p.16). Por lo tanto, las empresas -independientemente de su rol- compiten por el tiempo que los consumidores asignan para prestar atención al contenido.

Ahora bien, las formas de distribuir contenido varían, y la economía digital ha promovido una explosión de este al facilitar su producción y distribución (Evans, 2013, p. 314). En efecto, los productos y servicios de las industrias creativas se han visto impulsados cada vez más por la explosión de

\footnotetext{
Otra cosa cuya cantidad es limitada, y por la cual la demanda excede la oferta, es la atención de las personas. La atención es deseada para una variedad de propósitos comerciales, políticos y de otro tipo, y se obtiene con la ayuda de vallas publicitarias, periódicos, radio y otra clase de anuncios publicitarios. La expropiación de la atención del público general y su venta y explotación comercial constituyen un negocio lucrativo. En algunos aspectos, este negocio pareciera tener similitudes con aquel de los capitalistas sin escrúpulos de la era medieval (robber barons) y, por lo tanto, pareciera ser un tema propicio para la prohibición por parte de un estado controlado democráticamente por aquellos a quienes se les roba la atención [traducción libre].

2 Dado que la prioridad de todos los medios es mantener a su audiencia en su entorno durante el mayor tiempo posible a fin de extraer el mayor valor que puedan de ello (conocimiento detallado de los usuarios, exposición a publicidad etc.), las plataformas más tradicionales y los jugadores audiovisuales compiten directamente para atraer visitantes y son, en consecuencia, competidores directos en el mercado de pauta publicitaria [traducción libre] [el énfasis es nuestro].
} 
plataformas y la economía digital, entendiéndose a esta última como aquellos productos y servicios virtuales que son provistos a través de las redes de comunicación (Sartor, 2016), en particular en lo atinente a servicios over-the-top (en adelante, OTT). En un reciente estudio elaborado por la Comisión de Regulación de Comunicaciones de Colombia (en adelante, CRC), el organismo regulador precisó que, si bien no existe una definición unificada de servicios OTT, estos pueden ser entendidos como servicios de comunicaciones y aplicaciones de entrega de contenido e información a los que los usuarios finales acceden utilizando su propia conexión a Internet, sin la intervención de los operadores de telecomunicaciones tradicionales (2019, p. 30). De tal manera, los servicios OTT hacen referencia igualmente a los servicios de comunicaciones ofrecidos por un proveedor de servicios en línea ( $v$. gr. servicios de voz, mensajes, multimedia y audiovisuales), así como a las plataformas que se encargan de su distribución. En este orden de ideas, resulta ineludible la relación colaborativa entre la economía digital y la economía creativa, pues gracias a su interrelación es posible el crecimiento acelerado en los modelos de negocios en el ámbito cultural (Oxford Economics, 2014).

Por su parte, Wu concluye que es el medio de distribución, no el contenido, lo que atrae la atención de los usuarios (2017). Por lo tanto, las agencias de protección de la competencia deben aplicar algún tipo de prueba Small but Significant Non-Transitory Increase in Price (SSNIP) para determinar si la atención de los usuarios se centra en las redes sociales, el video, o combinaciones limitadas de contenido cultural (Evans, 2013, p. 315). Sin embargo, esta apreciación no tiene en cuenta que el tiempo que los consumidores dedican a consumir medios no ha aumentado. El tiempo sigue siendo un recurso escaso a pesar de que el crecimiento provea más tiempo para el ocio. Lo que ha sucedido es que los consumidores han reducido el tiempo dedicado a leer periódicos, libros o escuchar radio, sustituyéndolo por entretenimiento en redes sociales, plataformas de video bajo demanda pagas (Subscription Video on Demand, en adelante, SVOD; o Transactional Video on Demand, en adelante, TVOD) y/o en música online, el aumento más notable de las capacidades de transmisión y multitarea (Waldfogel, 2018).

Múltiples autores han sostenido que las empresas que buscan la atención de los consumidores compiten entre ellas, en al menos algún grado, en productos ampliamente diferenciados. De forma que, si una empresa recibe más atención de un consumidor, otra recibe menos ${ }^{3}$. Esta situación se eviden- cia de forma amplia en las diferentes estadísticas de consumo de medios. Según datos de Zenith, durante los últimos años, la televisión ha perdido su rol protagónico en el consumo de tiempo diario por audiencias, en tanto que plataformas de videos en línea han sustituido y atraído la atención de los usuarios, frente al consumo de televisión tradicional (Rodríguez, 2018a). Esta tendencia - teniendo en cuenta que la persona promedio pasa aproximadamente ocho horas por día consumiendo medios (Rodríguez, 2018a) - no proviene exclusivamente de un incremento en el tiempo promedio de los consumidores en medios, sino por intermedio del intercambio del consumo de unos medios por otros. Mientras que en el 2011, el consumidor promedio destinaba 80 minutos a consumir contenidos por Internet; en el 2019, esta cifra se elevó a 170 minutos, igualando el tiempo promedio viendo televisión (Rodríguez, 2018a). Las tendencias de consumo no solo están mediadas por la intensidad de la competencia en el mercado de la publicidad, sino también por las preferencias y decisiones de consumo en el mercado de contenido, cuyo valor es atraer la atención de los consumidores.

En este orden de ideas, resulta ineludible la relación colaborativa entre la economía digital y la economía creativa, pues gracias a su interrelación es posible el crecimiento acelerado en los modelos de negocios en el ámbito cultural (Oxford Economics, 2014).

¿Cómo podemos medir la relación cruzada entre los mercados de medios y tener una teoría adecuada y sólida del daño en la aplicación de la normativa de competencia? ¿Cómo debemos diseñar aquella teoría que nos permita medir mejor el público y el tiempo que los usuarios dedican al consumo de productos audiovisuales, para así poder establecer una delimitación más acertada del mercado afectado?

En este contexto, las autoridades de competencia alrededor del mundo están bajo la presión y el escrutinio públicos, debido a que los desarrollos en los mercados de tecnologías de la información - para la distribución de contenido- han aumentado la preocupación de que la aplicación de la ley de competencia, tal como está concebida actualmente, no sea adecuada para su propósito. Si bien es cierto que las empresas de tecnología han crecido de forma importante en los últimos meses, no parece haber evidencia suficiente que indique que el tamaño - por sí solo-genere un problema a nivel de libre competencia, ya que la evidencia en los mercados de contenidos digitales sugiere, por el contrario, que ha habido un incremento en el bie-

\footnotetext{
Véase Rodriguez (2018a).
} 
nestar de los consumidores a pesar de la concentración de mercado ${ }^{4}$. Este aumento en el bienestar de los consumidores ha derivado de aspectos como la innovación acelerada que caracteriza al entorno digital, el constante ingreso de nuevos oferentes al mercado - lo que amplía la variedad de los contenidos disponibles-, y la provisión de servicios gratuitos - al menos en términos monetarios- que proporcionan notables beneficios a los consumidores, emanados, en parte, del mejor entendimiento de las preferencias de estos que adquieren las plataformas, a raíz de la información que aquellas recopilan sobre sus usuarios (Shier, 2018) ${ }^{5}$.

El caso de los mercados de contenidos provee un importante y muy nutrido conjunto de posibles análisis que pueden sirven como base para construir una teoría del daño para los mercados dominados por la atención. En estos casos, el daño no debe medirse principalmente en términos de precios - como de forma indirecta lo hacen Wu o Evans - o por la contracción de la producción de contenidos u otros hipotéticos daños relacionados, sino con respecto a las limitaciones probables que los consumidores pueden tener para el acceso a una variedad de contenidos a los que prestar atención. Normalmente, la definición de un mercado es una cuestión de su sustituibilidad de un producto por otro producto. Esta aproximación simplemente lleva a una conclusión difícil: aunque no todo el contenido de la economía creativa proviene de la misma estructura de producción o de costos o tecnología de producción, todos los contenidos, al final, compiten por el tiempo de atención del consumidor (Evans, 2013, p. 314), independientemente de si el consumidor paga o no por ellos. Los consumidores pueden sustituir productos de atención, en muchos casos con indiferencia al precio, ya que todos representan medios diferentes para el entretenimiento o el tiempo libre del usuario ${ }^{6}$.
De tal manera, el presente documento, dentro del ámbito de la economía creativa y de la producción de contenido, se centrará puntualmente en la industria de contenidos audiovisuales, por tratarse de uno de los sectores económicos que está experimentando grandes avances y una transformación acelerada, impulsado por el progreso tecnológico y los hábitos cambiantes de los consumidores. A lo anterior, se le suma el despliegue de las conexiones de Internet fijo e inalámbrico cada vez más rápidas y la proliferación de dispositivos de visualización multipantalla.

Como se explicará, la producción de contenido es un negocio global altamente competitivo, en donde los agentes de mercado buscan desarrollar contenido que atraiga espectadores que se enfrentan a múltiples alternativas de visualización. De hecho, en un mercado de contenidos diverso y saturado, el éxito suele ser impredecible: los proveedores pequeños y grandes, por igual, tienen la capacidad de producir éxitos y fracasos ${ }^{7}$.

El mercado de producción y suministro de televisión es un mercado dinámico en el que existen fuertes presiones competitivas no solo porque hay muchos competidores tradicionales, sino también, porque el mercado está siendo influenciado por aplicaciones en línea y otras aplicaciones de medios digitales, "donde las necesidades de infraestructura ahora están estandarizadas y minimizadas y donde un único productor con un sitio web puede tener el mismo alcance [que los estudios]" (Ulin, 2014, p. 55).

\section{MERCADOS RELEVANTES: DISTRIBUCIÓN DE LA INDUSTRIA DE CONTENIDOS AUDIO- VISUALES Y PLATAFORMAS DIGITALES}

La industria audiovisual se compone de un contenido audiovisual que comprende películas,

Véase Waldfogel (2018).

Según lo denota la Directiva (UE) 2018/1808 del Parlamento Europeo y del Consejo (2018):

El mercado de la radiodifusión televisiva ha evolucionado y, por tanto, es necesaria una mayor flexibilidad por lo que se refiere a las comunicaciones comerciales audiovisuales y, en particular, a las normas cuantitativas para los servicios de comunicación audiovisual lineales y al emplazamiento de producto. La aparición de nuevos servicios, incluso sin publicidad, ha conllevado una mayor libertad de elección para los espectadores, que pueden pasar fácilmente a ofertas alternativas (considerando 32) [el énfasis es nuestro].

6 Véase Evans:

Antitrust analysis should therefore focus on competition for securing and delivering attention in considering market definition, market power, and competitive effects. Focusing on competition between specific products and services, rather than attention, could result in competition authorities and courts making either false-negative or false-positive errors in their decisions (2013, p. 314).

El análisis antimonopolio debería [...] centrarse en la competencia para captar y entregar atención al considerar la definición de mercado, el poder de mercado y los efectos competitivos. Enfocarse en la competencia entre productos y servicios específicos, en lugar de la atención, podría resultar en que las autoridades de competencia y las cortes comentan errores de falsos-negativos o falsos-positivos en sus decisiones [traducción libre].

7 Al respecto, Waldfogel señala que

Investors' inability to predict which products will succeed is not limited to movies; it's a generic feature of all of the cultural industries. Most musical albums fail, as do most books and new television shows. If the creative industries are to keep going, they must generate enough revenue to cover the costs of their successes and their failures (2018, posición 122). 
Figura 1. Estructura de la Industria de Contenido de Audiovisuales ${ }^{8}$

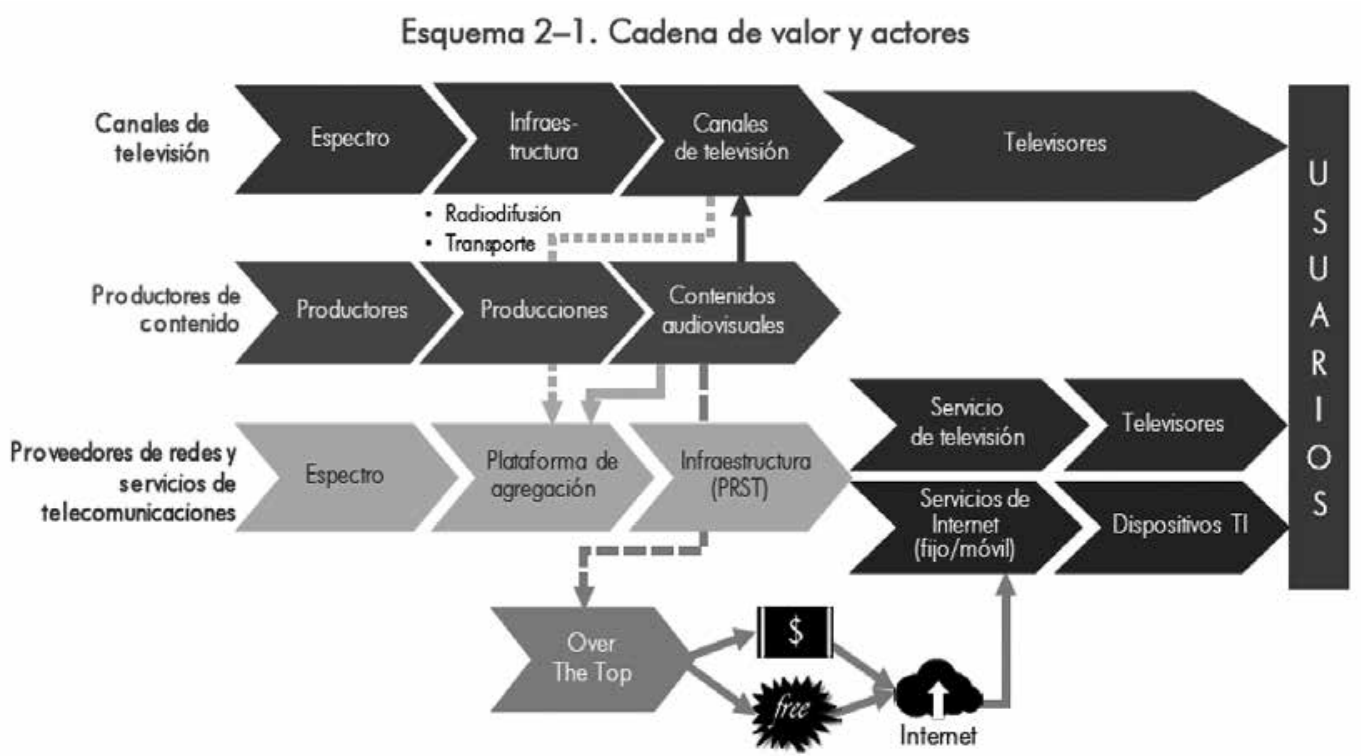

Fuente: Departamento Nacional de Planeación (2016, p. 19)

deportes, series de televisión, documentales, entre otros. Este contenido es producido, empaquetado y distribuido por numerosos actores en la cadena de suministro (Figura 1). Teniendo en cuenta la doctrina y jurisprudencia prevalente de las autoridades de competencia a nivel mundial, la cual considera la magnitud de la industria y los diferentes canales a través de los cuales el contenido llega al consumidor final, presentaremos a la industria audiovisual en dos cadenas de suministro diferentes: (i) la cadena de suministro de películas para teatros; y (ii) la cadena de suministro para contenido de televisión (incluyendo películas).

Como se explicará a continuación, las cadenas de valor de ambos productos audiovisuales se interrelacionan y se combinan, lo que permite que los activos utilizados para producir películas puedan, en determinadas circunstancias, utilizarse para producir contenido para televisión; o incluso, contenido para otras industrias no audiovisuales. Este enfoque permitirá un estudio más detallado de todos los mercados relevantes a la industria bajo examen.

El contenido audiovisual es producido (aguas arriba) por productores de medios, y distribuido en diferentes formatos por varios participantes (aguas abajo). El contenido puede ser exhibido en teatros o cines, difundido como video en casa y video por pedido, y ser agregado en ofertas de televisión (tales como canales de televisión y servicios ondemand). Se trata de una industria multinivel en la que múltiples participantes participan activamente en diversos niveles de la cadena de valor y la cual, en la actualidad, es desafiada por una ola de nuevos competidores.

\section{A. Dinámica competitiva en la industria de contenidos audiovisuales y plataformas digitales}

En términos generales, si bien en materia de producción de contenido y de suministro de películas y series, y otros contenidos audiovisuales, existen diferencias en lo que respecta al papel que desempeñan jugadores locales o internacionales, en la mayoría de países del mundo occidental confluyen una gran cantidad de participantes globales y nacionales, combinado con una producción in-house por parte de proveedores de contenidos audiovisuales minoristas verticalmente integrados, y con participantes como Netflix, Amazon Prime y YouTube, cuya relevancia ha venido incrementando en los últimos años. Así, organizaciones multinacionales como Warner Media, Universal, Paramount, Sony, Lionsgate, The Walt Disney Company y Twenty-First Century Fox, compiten por la atención de los usuarios con proveedores nacionales y locales,

8 Electronic Sell-through (en adelante, EST) se refiere a servicios de propiedad transaccional, por ejemplo, descargar para comprar, (el equivalente digital de un DVD, disponible en plataformas tales como iTunes de Apple y Amazon Prime). Como la ventana de Home Entertainment se abre antes y permanece abierta a través de las ventanas posteriores, EST está incluido en el diagrama con estos canales de distribución digital alternativos. Para completar, los distribuidores de películas también otorgan licencia para la proyección de películas por terceros en sitios que no son teatros ( $v$.gr. aviones, hoteles y colegios). 
revelando dinámicas distintas según las preferencias de los consumidores en cada país.

Por ejemplo, a nivel de servicios OTT de Video on Demand (en adelante, VoD), en el Reino Unido se destaca la importancia de los servicios públicos de radiodifusión (public service broadcasting) como la BBC, la cual, según un reciente estudio de Ampere Analysis, detenta el primer lugar entre la audiencia a través de su servicio de Broadcasting Video on Demand (en adelante, BVOD) (2019). De igual manera, las plataformas ITV Hub y All4, también ofrecidas por canales de televisión pública, ocupan el cuarto y quinto lugar (Ampere Analysis, 2019). En Alemania, Francia y Dinamarca, se observan dinámicas similares: los servicios BVOD de servicios de canales como ZDF, TV1 y DRTV ocupan el segundo (para los primeros dos casos) y tercer lugar en audiencias (Ampere Analysis, 2019). En contraste, en países como Estados Unidos, España y Colombia, YouTube lidera el mercado de servicios OTT de VoD, y en segundo lugar se encuentra Netflix, que lidera el mercado en México y Brasil $^{9}$.

En el mercado de servicios OTT de VoD, la dinámica competitiva es cada vez mayor, pues con el auge de servicios basados en Internet y de las nuevas tecnologías, se ha facilitado el ingreso de nuevos competidores al mercado de suministro de contenido audiovisual, lo que ha producido un incremento en la oferta de servicios audiovisuales minoristas que se proveen directo a los consumidores. Según Ampere Analysis, tales servicios representan más del $50 \%$ del tiempo de visualización reportado en diez de las economías más desarrolladas del mundo occidental ${ }^{10}$ (2019). Este fenómeno se ha visto impulsado por tres factores que redundan en mayor conveniencia para los consumidores: (i) distribución, en la medida en que los usuarios pueden acceder al contenido vía Internet (por lo que puede visualizarse fuera del hogar y sin necesidad de instalación de equipos sofisticados); (ii) visualización, en tanto se puede acceder a la biblioteca del proveedor de video en cualquier momento; y (iii) precios menores y mayor flexibilidad en los contratos con los usuarios, dada la menor estructura de costos y la existencia de menos niveles (tiers) comparado con la televisión por suscripción (Ampere Analysis, 2019, p. 3).

Los servicios basados en Internet que ofrecen contenido directo a los consumidores pueden clasificarse en dos grandes grupos: (i) video bajo deman- da financiado por publicidad (Advertising Financed Video on Demand, en adelante, AVOD); y (ii) video bajo demanda financiado por el usuario (User Financed Video on Demand, en adelante, PVOD). En este último es posible identificar dos modalidades: pague por ver (pay-per-view) o precio fijo (flatrate pricing) (Budzinski \& Linstädt-Dreusicke, 2018, p. 5). Así, se incluyen dentro del primer grupo, AVOD, los servicios de Video Gratis Por Demanda (Free Video on Demand, en adelante, FVOD, v.gr. YouTube); y dentro del segundo, PVOD, los de Video Transaccional por Demanda (TVOD, v.gr. iTunes) y de Video por Suscripción por Demanda (SVOD, v.gr. Netflix). En adición a lo anterior, se encuentran los servicios de televisión abierta (Free-to-Air, en adelante, FTA; v.gr. Caracol, RCN, BBC), emisoras STV y sitios web de transmisión por demanda (on-demand).

Por otro lado, aguas abajo, en la distribución de películas para su exhibición en cines, el mercado está caracterizado por ostentar una competencia significativa por el espacio limitado de pantalla entre distribuidores internacionales, regionales y locales. En la práctica, sucede que los agentes de mercado fungen tanto como productores de contenido y de suministro, como de distribuidores de este; es decir, se presentan integraciones verticales para la distribución de películas. Igualmente, sucede que los productores de contenido y de suministro utilizan distribuidores externos independientes en algunos países, caso en el cual, los terceros independientes son los que contratan directamente con quienes exhiben las películas.

Asimismo, debe considerarse que varios agentes del mercado en el segmento de la distribución distribuyen su contenido al (i) agregarlo a sus propios canales lineales de marca, compitiendo con una variedad de ofertas de emisores públicos y privados y otros agrupadores de contenido; y (ii) al licenciarlo (por título, por paquete o por producto) a operadores de cable, proveedores minoristas de canales de televisión abierta y plataformas de televisión minorista. Este contenido compite con aquel que es producido por proveedores de canales y plataformas de televisión, y a su vez, con el que estos competidores obtienen de otros productores.

El sector audiovisual es dinámico y está experimentado una transformación acelerada, impulsada por avances tecnológicos y hábitos cambiantes de los consumidores. El despliegue de conexiones

9 Véase Comisión de Regulación de Comunicaciones (2020, pp. 24-28); SAI Derecho y Economía (2018, pp. 132-133); y Russo (2019).

10 Los países analizados son: Alemania, Dinamarca, España, EE. UU., Francia, Italia, Países Bajos, Polonia, Reino Unido y Suecia (Ampere Analysis, 2019). 


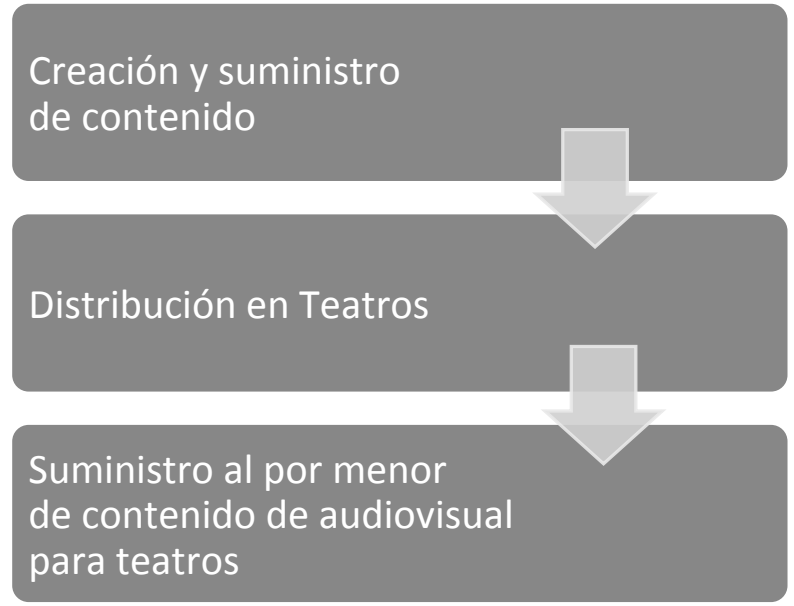

Fuente: Elaboración propia

de Internet fijo e inalámbrico cada vez más rápidas, el aumento exponencial en la distribución de todo tipo de contenido audiovisual y la proliferación de dispositivos de visualización multi-pantalla ha conducido a la entrada de nuevos competidores y modelos de negocio a nivel mundial, incluyendo un incremento significativo del contenido disponible para los consumidores y una mayor competencia entre los productores y distribuidores de contenido ${ }^{11}$.

La tecnología está cambiando la oferta y la demanda en la industria. Por el lado de la oferta, la digitalización ha reducido las barreras para la creación y distribución de contenido. Por el lado de la demanda, dramáticas mejoras en los sistemas de audio y video para el hogar y la velocidad de la banda ancha han brindado a los consumidores muchas más opciones, llevando a los emisores a mejorar sus instalaciones de cines como respuesta a lo anterior.

Adicionalmente, con las mejoras en la infraestructura tecnológica para la entrega de contenido de video, incluida la distribución móvil, los consumidores esperan cada vez más, y están dispuestos a consumir contenido a pedido, bajo su control y conveniencia, dentro de una amplia gama de dispositivos y pantallas. Así las cosas, como lo ilustran estos servicios, los avances tecnológicos han incrementado considerablemente el número y diversidad de competidores en el sector audiovisual.
En este escenario, y en lo que concierne a las plataformas OTT, Ampere Analysis ha establecido que los niveles de ingresos no evidencian una fuerte correlación con el volumen de contenido ofrecido dentro de la plataforma; por el contrario, la exclusividad frente a contenidos clave ( $v$.gr. eventos deportivos, películas y series populares) y la calidad del contenido son los factores determinantes del éxito de estos oferentes (2019, p. 10).

\section{B. Productos ofrecidos en la industria de contenidos audiovisuales y plataformas digitales}

1. Mercado de producción y suministro de películas para su presentación en cines

En primer lugar, debe resaltarse que el contenido audiovisual es realizado por los productores de medios y distribuido en una variedad de formatos diferentes por distintos actores de la cadena. En cuanto al mercado de películas para la presentación en teatros, este se compone de tres niveles, tal como se ilustra en la Figura 2.

\section{a. Producción y suministro de películas para presentación en teatro}

Este nivel de la cadena de suministro abarca la etapa de preproducción (preparatoria), etapa de producción (filmación y producción de video) y etapa de posproducción (edición y adición de efec-

11 De igual manera, no debe desconocerse que la dinámica del sector también se ve afectada por la "piratería" de contenido audiovisual, que es una constante amenaza para los ingresos y las inversiones. Los avances tecnológicos pueden aumentar los riesgos que la piratería representa para los productores y distribuidores de contenido, lo que requiere un control constante y una inversión en medidas regulatorias para solucionarlo. Incluso podría llevar a una interrupción completa de la organización del mercado, como la que se ha presentado en la industria de la música en las últimas décadas 
tos audiovisuales). En la cadena de valor teatral, la producción cinematográfica se monetiza mediante la distribución de películas en cines, donde los productores de cine pueden estar verticalmente integrados, en cuyo caso sus propias organizaciones de distribución supervisan la distribución de los cines.

Alternativamente, los productores de cine pueden celebrar contratos con un tercero distribuidor, quien puede ser el brazo de distribución de otro estudio cinematográfico o una compañía independiente a la que le proporcionarán derechos de distribución. Bajo este modelo, los productores de películas otorgan la licencia de los derechos de distribución para un país o territorio a los distribuidores locales o internacionales de películas (Radicación 12-226871, 2012).

Por un lado, con respecto a la distribución en teatros, la actividad económica del distribuidor está relacionada con la comercialización de la película, la negociación de los contratos de alquiler de la película con los presentadores y el recaudo de la tarifa de alquiler (Caso M.1219, Seagram/Polygram, 1998, párr. 44). El distribuidor también hace los acuerdos necesarios con relación a las copias de las películas entregadas a los teatros y otorga sublicencias de derechos de presentación a los presentadores, tales como operadores de teatros (Caso M.2050, Vivendi/Canal+/Seagram, 2000, párr. 16).

Por otro lado, en cuanto al suministro al por menor de contenido fílmico en teatros, los distribuidores a teatros otorgan sublicencias de derechos de presentación a presentadores de películas o minoristas, es decir, operadores de cine $u$ operadores de cadenas de cine. La actividad económica de la presentación consiste en la comunicación pública de la película producida, a través de la presentación en cines. Es en esta última etapa de la cadena de suministro en donde la película producida o el contenido se da a conocer al consumidor final (Izquierdo Castillo, 2007, p. 72).
Por último, amerita destacar cómo el factor éxito juega un papel relevante en la participación de mercado de los agentes que desarrollan la actividad de suministro de películas para teatros. Según expresa la Superintendencia de Industria y Comercio de Colombia (en adelante, SIC) en su análisis de la reciente integración entre The Walt Disney Company y Twenty-First Century Fox: "Ias características de este mercado hacen que sea un negocio no previsible, pues, el poder de mercado que obtenga un agente (productores) no dependerá de sí mismo, sino del éxito de las películas que produce" (Resolución 92709, 2018, p. 26) [el énfasis es nuestro].

\section{Mercado de contenidos de televisión}

Por su parte, la cadena de suministro de la industria de la televisión se compone de tres niveles, como se ilustra en la Figura 3 a continuación.

a. Producción y suministro de contenido de televisión

El contenido de televisión puede contener una amplia gama de formas, incluidas las series de televisión, deportes en vivo, juegos, documentales, dibujos animados, eventos en vivo y películas. Los propietarios de derechos y productores de contenido comprenden una multiplicidad de actores internacionales y locales existentes, desde organizaciones deportivas hasta compañías de producción de televisión. Este nivel de la cadena de suministro incluye actores como Warner, Universal, Sony, Paramount, Lionsgate y otros, así como también participantes recientes, como Amazon y Netflix.

Por su parte, las plataformas de televisión se esfuerzan por crear una propuesta distintiva para atraer a los consumidores y anunciantes, ofreciendo sus servicios a través de diferentes modelos (como televisión por suscripción o televisión abierta) y diferentes medios de transmisión (como terrestre, por cable, por satélite o en Internet). 
Ahora bien, tomando la definición estipulada en la Ley 182 de 1995, por la cual se reglamenta el servicio de la televisión, la palabra 'televisión' hace referencia a un servicio de telecomunicaciones que ofrece programación dirigida al público en general o a una parte de él, que consiste en la emisión, transmisión, difusión, distribución, radiación y recepción de señales de audio y video de manera simultánea. Dichas transmisiones tradicionalmente toman la forma de servicios lineales gratuitos o de pago, en los que el horario y la secuencia de la programación está determinada por el presentador, pero que ahora también están ampliamente disponibles por pedido. Estos servicios no lineales les permiten a los consumidores ver el contenido después de la primera emisión, o seleccionar el programa que quieren ver desde un catálogo de contenido disponible, y cambiante.

Así, las compañías activas en la producción y suministro de contenido audiovisual para televisión producen dicho contenido, ya sea para: (i) el uso interno de sus propios canales de televisión o servicios de televisión al por menor si están integrados verticalmente en la operación y en el suministro al por mayor de canales de televisión y/o en el suministro al por menor de servicios de televisión (producción cautiva); o (ii) para el suministro a terceros clientes (producción no cautiva), que generalmente comprenden proveedores de canales de televisión, incluidos minoristas de servicios de televisión, que luego incorporan el contenido a los canales de televisión lineales (que proporcionan televisión que se ve según sea programada), u operadores de plataforma de contenido, que luego venden los contenidos de televisión a los usuarios finales de forma no lineal, incluso a través de Internet.

Ahora, el suministro a terceros clientes comprende una amplia variedad de formas: series de televisión, películas hechas para televisión, premios (como los premios Oscar), documentales, caricaturas, espectáculos de juegos, eventos en vivo, deportes y películas. Con respecto a esta última, después de la presentación en salas, la película podrá ser licenciada para su emisión o venta, siendo la televisión uno de los posibles puntos de distribución.

También se debe tener en cuenta que las inversiones en marketing para la versión inicial impulsan los mercados aguas abajo, por lo que el éxito de la película después de su estreno en salas depende del marketing inicial de la película (Ulin, 2014, pp. 38-42).

De igual modo, el contenido también tiene licencia para su distribución en servicios de televisión abierta. Estos servicios pueden ser recibidos por cualquier espectador dentro del rango de transmisión sin suscripción, y generalmente son publicitados o financiados con fondos públicos. A modo ilustrativo, en Colombia, alrededor del $60 \%$ del contenido de la televisión abierta se produce internamente (in-house), mientras que los proveedores de canales de televisión por suscripción adquieren la mayoría de su contenido por parte de terceros (Comisión de Regulación de Comunicaciones, 2015, p. 12).

En cuanto a la población objetivo, esta es amplia y varía dependiendo del contenido audiovisual. Es importante señalar que, como concluye el estudio de mercado realizado por el Departamento Nacional de Planeación, la evolución de los servicios por pedido (on-demand) ha llevado a una nueva caracterización del perfil de consumo del contenido audiovisual (2016) y ha aumentado la disponibilidad y la visibilidad de alternativas para los consumidores. Cada vez es más común ver múltiples opciones disponibles una al lado de la otra, en la misma plataforma. Por ejemplo, Apple puede ofrecer simultáneamente a los consumidores la opción de comprar, alquilar o incluso mirar (es decir, reproducir) contenido de películas junto a series de televisión. En la misma línea, las recomendaciones de visualización de Netflix también presentan contenido de películas y series de televisión, paralelamente, en la misma plataforma.

Las empresas que producen contenido no específicamente destinado a la televisión tienen la capacidad de sustituir su oferta y participar en la producción de contenido de televisión, principalmente porque existe una similitud entre los procesos de producción de los diferentes contenidos. Desde una perspectiva de análisis de costos, se deben considerar dos factores: (i) "los estudios producen y financian proyectos dentro de una amplia gama de presupuestos" (Ulin, 2014, p. 29) [traducción libre]; y (ii) la tecnología ha reducido el costo de producción de contenidos, haciendo a esta industria accesible para una gama más amplia de compañías de producción.

En este sentido, el contenido televisivo puede ser elaborado por compañías de producción cinematográfica u otras productoras cuyo principal medio de comunicación no sea la televisión, desde aquellas que son independientes, hasta los grupos aliados para proyectos específicos y grandes estudios (Departamento Nacional de Planeación, 2016).

Además, gracias a que Internet actúa como un canal para la distribución de contenidos audiovisuales OTT, existen varios competidores nuevos, actuales y potenciales. El sector audiovisual está 
en constante desarrollo y rápida innovación, impulsado por cambios fundamentales en el comportamiento del consumidor, la evolución tecnológica y la entrada agresiva de nuevos competidores. El contenido producido por el consumidor, disponible en plataformas como YouTube, Vimeo, Facebook y sitios locales para compartir videos está atrayendo cada vez más la atención de los espectadores, ejerciendo, por tanto, mayores presiones competitivas. El contenido producido para videojuegos (que incluye ver a otros jugando) también compite por la atención del espectador, y las investigaciones sugieren que, en el 2017, Twitch, la plataforma principal para ver este tipo de contenido ya contaba con más de 600 millones de espectadores (Valens, 2017). Al respecto, resulta pertinente traer a colación la Directiva (UE) 2018/1808 del Parlamento Europeo y del Consejo, la cual reconoce expresamente a los medios sociales como

un importante medio para compartir información, entretener y educar, en particular mediante el acceso a programas y a vídeos generados por usuarios. Estos servicios de medios sociales deben incluirse en el ámbito de aplicación de la Directiva 2010/13/UE [Directiva de Servicios de Comunicación Audiovisual] porque compiten por la misma audiencia e ingresos que los servicios de comunicación audiovisual (2018, considerando 4) [el énfasis es nuestro] ${ }^{12}$.

De tal suerte, es posible aseverar que el contenido generado por el usuario, las series de televisión y las películas compiten por la atención del consumidor.

De igual manera, las series de televisión, los videojuegos y las películas, compiten para obtener dicha atención. Además, los proveedores de contenido no cinematográfico, como representaciones teatrales o musicales en vivo, ejercen una presión competitiva adicional para las películas exhibidas en teatros. Las proyecciones de este tipo de contenidos, que han sido posibles gracias a los avances tecnológicos que permiten transmisiones de banda ancha/satélite a los cines, son cada vez más populares para actuaciones de alto perfil y en áreas que no están cerca de eventos en vivo.

Por lo anterior, es posible afirmar que, entre otros, los servicios sustitutos para la producción cinematográfica son (i) los estudios que producen contenidos de televisión; (ii) las compañías productoras en general cuya salida primaria no son los teatros; (iii) los proveedores de contenido no cinematográfico, como distribución de representaciones teatrales o musicales en vivo; (iv) los productores de contenido en línea; y (v) el contenido producido por el consumidor.

Adicionalmente, hay muchos productores internacionales de contenido de alta calidad que participan en este mercado, incluidos Warner (y su filial HBO), Universal, CBS, Sony y Lionsgate. Sin embargo, el éxito pasado no proporciona ninguna garantía de éxitos futuros, incluso para los productores establecidos: Minority Report (21CF), American Odyssey (NBC), Game of Silence (NBC), Camelot (Starz), Containment (Warner) y Of Kings and Prophets $(A B C)$ son ejemplos de fracasos televisivos recientes que fueron cancelados antes o al final de su primera temporada.

Recientes entrantes al mercado como Netflix, con Stranger Things y diversos otros títulos, y Amazon Prime producen una gran cantidad de contenido original para televisión. Apple recientemente ingresó al mercado con su servicio Apple TV+, el cual se compone en un porcentaje significativo por contenido original, y YouTube, que es parte del grupo empresarial Alphabet, el cual controla Google, también está produciendo cada vez más contenido original, tanto para su plataforma de acceso gratuito como para su servicio de suscripción YouTube Red.

Además, el contenido producido por los mismos usuarios, que está disponible en plataformas como YouTube, Vimeo, Facebook y sitios nacionales para compartir videos, está captando cada vez más atención de los televidentes y, por lo tanto, ejerce una presión competitiva significativa.

\section{b. Operación y suministro mayorista de canales de televisión}

Los canales de televisión mayoristas ofrecen a los operadores de cable contenido audiovisual organizado en una secuencia lineal, bien produciendo su propio contenido audiovisual o bien licenciándolo de terceros. Dichos canales también ofrecen espacio publicitario a terceros. Los canales lineales están distribuidos a través de plataformas de televisión abierta que suministran canales a los consumidores sin costo, a través de plataformas de

12 Así, en tanto el ofrecimiento de programas y videos generados por los usuarios represente una funcionalidad esencial del servicio de los medios/redes sociales, es decir, cuando no se trate de una funcionalidad meramente accesoria o constituya una parte mínima de las actividades del servicio; el mismo se sujetará a las obligaciones aplicadas a los prestadores de servicios de comunicación audiovisual por virtud de la Directiva referida. Véase la Directiva (UE) 2018/1808 del Parlamento Europeo y del Consejo (2018, considerando 5). 
televisión por suscripción (en las que el espectador debe pagar una tarifa de suscripción), o como servicios OTT.

Por su parte, los proveedores de canales de televisión adquieren el contenido de terceros y lo empaquetan en canales de marca; de este modo, pueden crear contenido no lineal para ser usado a través de servicios de VoD. En este eslabón de la cadena de suministro, los proveedores de televisión abierta también deben estar incluidos, dado que constituyen un insumo para las plataformas de televisión por suscripción (Comisión de Regulación de Comunicaciones, 2015, p. 12), afirmación que cobra fuerza en aquellas jurisdicciones que establecen obligaciones de must-carry y/o must-offer en los mercados de radiodifusión. Por ejemplo, la obligación de los proveedores de televisión por suscripción de ofrecer, dentro de sus paquetes de canales, los canales de televisión abierta, y la obligación de éstos de suministrar sus contenidos a los primeros, respectivamente ${ }^{13}$.

Además de la transmisión de televisión abierta y televisión por suscripción, los canales de televisión son distribuidos a través de soluciones basadas en Internet. Aunque esta modalidad de transmisión se encuentra en las primeras etapas de desarrollo en América Latina, existen varios servicios de transmisión libre (OTT) que ya se ofrecen en la región, tales como DirecTV Play, Claro Video, HBO Go, al igual que servicios de los proveedores locales, por ejemplo, Caracol Play en Colombia y OiTV en Brasil.

Por ende, según lo analizado por el Departamento Nacional de Planeación, la distribución de contenido puede hacerse a través de la televisión u OTT, mediante aplicaciones o páginas web (2016). En este sentido, los proveedores de contenido tienen numerosos medios alternativos a los que pueden otorgar licencias de contenidos audiovisuales, incluidos otros proveedores de canales (Caracol Televisión, RCN Televisión, Discovery Networks, entre otros), minoristas tradicionales de televisión (v.gr. DirecTV, Claro, Movistar), y el número cada vez mayor de nuevos jugadores OTT (v.gr. Netflix, Movistar Video, Caracol Play, WinSports Online, Claro Video, Apple TV).
De hecho, debido a las nuevas plataformas de distribución, los servicios tradicionales de este rubro han tenido la necesidad de innovar para hacer frente a la nueva presión competitiva (Departamento Nacional de Planeación, 2016). Ello ha llevado al Departamento Nacional de Planeación a concluir que el crecimiento y desarrollo de las plataformas de transmisión libre (OTT) en un escenario de competencia directa con los modelos tradicionales de televisión ha generado un cambio en la cadena de valor tradicional del contenido audiovisual. En el caso colombiano, este cambio en el segmento de distribución del mercado se evidencia por el hecho de que los operadores de servicios tradicionales están ingresando en modelos de negocios basados en Internet:

Aunque las cifras no coinciden entre sí, el estudio que proporcionó las estadísticas más controvertidas fue el desarrollado por IMS y ComScore. Según este estudio, en Colombia hay más usuarios viendo Videos por Pedido que televisión abierta (80\% frente a 66\%). Esto significa que las plataformas como Youtube y Netflix tienen más espectadores que los canales tradicionales [...]. De hecho, los canales tradicionales también se han visto afectados por los efectos del video por pedido, que cada vez aleja más a los usuarios de televisión (Semana, 2016) ${ }^{14}$.

Sobre la base de lo anterior, se puede sostener que, entre otros, estos son los productos sustitutos de los canales de televisión:

1. Video independiente por pedido (Standalone Free Video on Demand, FVOD, v.gr. YouTube), el cual es gratuito para el espectador, es decir, se puede acceder sin el pago de una tarifa de suscripción, pero al igual que otros canales de televisión abierta, obtienen importantes ingresos de publicidad, que remunera a los productores de contenido;

2. Entretenimiento en el hogar, en forma de productos físicos (como DVD y Blu-Ray) o venta electrónica directa (EST), que permite a los consumidores descargar una copia digital de la película para su propiedad o

13 A nivel regional, ejemplos de estas disposiciones de encuentran en México y Chile, en donde se aplican ambas previsiones, y Colombia y Brasil, en donde existe una obligación de must-carry en cabeza de los proveedores de televisión por suscripción.

14 Asimismo, el artículo señala que

[e]l estudio de IMS y ComScore reveló que los colombianos dedican buena parte de su tiempo libre a ver video en su celular. Los smartphones, según el diagnóstico, "se utilizan en promedio 6,2 horas para ver video digital, casi la mitad del tiempo total dedicado a videos, mientras que los computadores acaparan 4,8 horas y las TV conectadas 4,5 horas" (Semana, 2016). 
adquirir derechos ilimitados para transmitir el contenido desde una plataforma digital o depósito de almacenamiento virtual (virtual storage locker);

3. Video Transaccional por Pedido (Transactional Video on Demand, TVOD, v.gr. iTunes), que es un 'alquiler digital' que permite a los usuarios acceder a la película por un período limitado, a cambio de un pago único;

4. Video de suscripción por pedido (Subscription Video on Demand, SVOD, v.gr. Netflix), en el que el consumidor paga una tarifa de suscripción para acceder a una biblioteca de contenido.

Por último, es importante precisar que, por lo general, la aproximación al mercado de suministro mayorista de canales de televisión no se ha hecho de modo segmentado por géneros (v.gr. deportes, ciencia, historia, documentales, infantiles, noticias, etc.), pues ello puede desconocer la realidad del mercado, donde tanto minoristas (operadores de televisión) como consumidores finales (espectadores) buscan acceso a una amplia gama de contenidos ${ }^{15}$. Según lo expresa el Instituto Federal de Telecomunicaciones México (en adelante, IFT), en su análisis de la reciente operación de integración entre The Walt Disney Company y Twenty-First Century Fox, las categorías programáticas son complementarias en la provisión de contenidos audiovisuales a los usuarios finales, en tanto la motivación subyacente a estos al adquirir servicios de televisión - de pago- es ampliar el espectro de opciones de contenidos y canales a su disposición (Acuerdo P/IFT/110319/122, 2019, pp. 68-71).

En efecto, tanto los operadores de televisión abierta como cerrada generalmente adquieren (y/o producen) un amplio portafolio de géneros y programas audiovisuales para asegurar paquetes atractivos que satisfagan los múltiples intereses de los consumidores finales y obtener así mayores niveles de audiencia. La mixtura de géneros es, por tanto, la base de la competencia en el mercado minorista de canales de televisión y, de manera general, ningún género, por sí solo, tiene la habilidad de determinar el comportamiento del consumidor final.

\section{c. Suministro de espacio publicitario}

Los medios de comunicación, en este caso la televisión, son el vehículo usado para transmitir la publicidad de la persona o de la compañía, pública o privada, interesada en informar o promocionar la existencia de sus bienes, productos o servicios (Resolución 20065, 2010). Los canales de televisión compiten con otras compañías de medios por los ingresos del mercado de publicidad, no solamente con otros canales de televisión sino también con otros medios de comunicación tales como periódicos, radio y revistas (Comisión de Regulación de Comunicaciones, 2015, p. 54).

La SIC ha considerado que el suministro de espacio publicitario a través de diferentes medios constituye un mercado único dado el alto grado de sustituibilidad debido al efecto que el cambio de precios relativos tiene sobre la demanda ( $R a-$ dicación 17-192278, 2017). En efecto, al analizar solo los medios digitales, se han realizado estudios concluyentes que demuestran el impacto positivo que tiene el cambio de los precios relativos de la publicidad en los medios digitales en la demanda de publicidad en medios no digitales.

Por su parte, Goldfarb y Tucker concluyen en su estudio que el mercado no digital podría disciplinar el mercado digital (2011). Por otro lado, según Ratliff y Rubinfield, la evidencia empírica sugiere que la publicidad digital limita los precios de la publicidad no digital (2010). En este sentido, debido al fenómeno de convergencia de medios y plataformas, el suministro de espacio publicitario a través de diferentes medios (revistas, radio, aplicaciones y periódicos) debe considerarse como un sustituto del espacio publicitario televisivo (Radicación 16335436, 2016).

Además, el estudio de mercado realizado por el Departamento Nacional de Planeación evidenció que la entrada de nuevos medios digitales (especialmente los servicios OTT) ha llevado a la migración de anuncios de medios tradicionales a medios digitales. Esto significa que la entrada de nuevos medios digitales que permiten el acceso al contenido audiovisual ha tenido efectos en la capacidad de la televisión abierta ( $y$, en esa lógica, la televisión en general) para generar

15 Al respecto, pueden consultarse las siguientes decisiones de autoridades de competencia: la Resolución 92709 (2018) de la Superintendencia de Industria y Comercio (Caso The Walt Disney Company-Twenty-first Century Fox); la Comunicación de la Superintendencia de Industria y Comercio con Radicación 17-360642-1 (2017) (Caso Discovery Communications Inc.-Scripps Networks Interactive Inc.); El Estudio Económico de la Superintendencia de Industria y Comercio con Radicación 17-38927 (2017) (Caso AT\&T Inc. y Time Warner Inc.); la Comunicación de la Superintendencia de Industria y Comercio con Radicación 13-225821-2 (2013) (Caso Fox Laptv L.L.C.-Paramount Laptv Inc.); y el Informe de aprobación de la Fiscalía Nacional Económica del Caso The Walt Disney Company-Twenty-First Century Fox (Rol de la causa FNE F155-2018, 2019). 
ingresos a través del ofrecimiento de espacios publicitarios (Departamento Nacional de Planeación, 2016).

Por lo anterior, es posible afirmar que, entre otros, los servicios sustitutos para el suministro de espacio publicitario son: (i) publicidad a través de la radio; (ii) publicidad a través de revistas; (iii) publicidad a través de posters; (iv) publicidad a través de periódicos; ( $v$ ) publicidad en vallas publicitarias y publicidad exterior en general; (vi) publicidad a través de páginas web; (vii) publicidad a través de aplicaciones (Waze, Game apps); (viii) publicidad en salas de cine; y (ix) publicidad a través de redes sociales (Facebook, Instagram).

Puntualmente la televisión por suscripción se enfrenta a una fuerte competencia en el mercado de suministro de espacio publicitario, por dos motivos: (i) la publicidad no es su principal actividad económica; y (ii) la audiencia de la televisión por suscripción no es lo suficientemente significativa como para atraer más inversión en publicidad. De hecho, a diferencia de la televisión abierta (FTA TV), donde la publicidad corresponde a alrededor del $80 \%$ de sus ingresos totales, los canales de televisión por suscripción (Pay TV) no dependen principalmente de la publicidad (Comisión de Regulación de Comunicaciones, 2015, p. 54). Además, como se trata de un mercado de dos lados, la capacidad de un canal para vender espacios publicitarios depende de su capacidad para atraer espectadores (Comisión de Regulación de Comunicaciones, 2016, p. 51).

\section{d. Suministro minorista de contenido de televisión}

Los minoristas de contenido de televisión - tales como Claro, DirecTV, Movistar- obtienen licencias para transmitir los canales de televisión por parte de proveedores mayoristas y los agregan para ser vendidos como paquete al consumidor final (paquete de canales) (Departamento Nacional de Planeación, 2016). En este espacio también se encuentran canales de televisión abierta, ya que entregan su señal a los consumidores finales $\sin$ cargo alguno. Los proveedores de contenido en línea, como Netflix, compran y producen contenido para ser distribuido como OTT.

3. Otros mercados relevantes dentro de la industria audiovisual

Para concluir con los mercados relevantes enmarcados en la industria de contenido audiovisual, cabe advertir que las firmas que ofrecen productos circunscritos a los mercados de producción y suministro de películas para su presentación en cines y al mercado de contenidos de televisión, usualmente, también participan en mercados conexos. Es decir, las firmas que compiten en la industria de contenidos audiovisuales se desenvuelven igualmente en mercados como (i) el mercado de productos de consumo; (ii) el mercado de libros y revistas; (iii) el mercado de licenciamiento de derechos musicales; y (iv) el mercado de licenciamiento de contenido para desarrolladores de videojuegos, entre otros.

En el mercado de productos de consumo, participan agentes a través de licencias de derechos de propiedad intelectual para la fabricación de una amplia gama de productos de consumo tales como: juguetes, vestuario y calzado, textiles para el hogar, cuidado de salud y belleza, relojes y joyería, papelería, etc. Por otro lado, en el mercado de libros y revistas, es común que los productores de contenidos audiovisuales otorguen licencias sobre los derechos de libros y revistas a editores en el país, pudiéndose suscribir los contratos por fuera de Colombia.

En el mercado de licenciamiento de derechos musicales, los agentes desarrollan, producen, comercializan y distribuyen música grabada en el mundo entero. Estos agentes igualmente pueden participar en los mercados antes mencionados. Lo anterior incluye tanto la música que contratan para sus películas y programas de televisión, como la música que se graba y distribuye por o en nombre de sus respectivos sellos musicales.

Así, las editoras musicales pueden estar activas en dos niveles de la cadena de valor. Aguas arriba, suministran servicios de publicidad para artistas. Estos servicios incluyen la firma de artistas y la provisión de apoyo tanto financiero, como de comercialización y de carrera. Como contrapartida a estos servicios, los artistas transfieren los derechos de su obra musical a la editora u otorgan a esa editora un interés económico en la obra musical, de este modo, le conceden, a su vez, el derecho de obtener una porción de las regalías recaudadas.

Aguas abajo, las editoras musicales participan en la explotación de las obras de los artistas en el desarrollo de sus contratos y durante un periodo después del vencimiento del contrato (denominado periodo de retención). En ese nivel, otorgan directamente licencias de uso de las obras musicales a usuarios contra el pago de regalías, o reciben una parte de las regalías recaudadas por las compañías recaudadoras (por las licencias emitidas por las compañías) por la promoción del trabajo del artista. 


\section{PLATAFORMAS Y MERCADOS AUDIOVISUA- LES DE CARA AL RÉGIMEN DE LIBRE COMPE- TENCIA}

Como se ha mencionado a lo largo de este documento, la industria de producción y suministro de contenido audiovisual es una industria altamente competitiva. Esto ha sido reconocido recientemente por la SIC, en la revisión de la adquisición de Time Warner por AT\&T, al afirmar sobre la oferta de canales de televisión lo siguiente:

"En cuanto a los competidores, en el mercado mayorista [oferta de canales de televisión] hay un número significante de participantes internacionales, además de varios canales nacionales abiertos de televisión (privados, regionales o institucionales)" (Superintendencia de Industria y Comercio, Resolución 92709, p. 14).

Adicionalmente, teniendo en consideración el estudio realizado por la CRC, utilizado por la SIC como insumo para el Estudio Económico preparado para la transacción entre AT\&T y Time Warner, el mercado para el suministro mayorista de canales de televisión está fragmentado, razón por la cual las probabilidades de prácticas restrictivas de la competencia derivadas de ejercicios de poder de mercado por parte de agentes particulares son bajas (Comisión de Regulación de Comunicaciones, 2015, p. 36).

Así las cosas, cabe aseverar que, aguas arriba, existe una multiplicidad de productores y proveedores de contenido televisivo que compiten fuertemente entre sí (v.gr. Warner, Universal, Sony, Paramount y Lionsgate a nivel mundial y Caracol, RCN, Teleset, y RTI a nivel local), todos produciendo contenido de alta calidad, innovadores y altamente demandados. Estas opciones de contenido pueden ser ofrecidas a través de una amplia variedad de canales. En consecuencia, aguas abajo, en el mercado de distribución minorista de contenido de televisión, los consumidores tradicionales (televisión abierta y televisión por suscripción minoristas) tienen un extenso catálogo de productos y proveedores de los cuales elegir, junto con su propia producción audiovisual/de canales.

Dichos operadores de televisión en Colombia, muchos de ellos panregionales, son consumidores fuertes con un alto poder de negociación, al tener la mayor audiencia (caso de los operadores de televisión abierta privada: Caracol y RCN) y/o pertenecer a importantes conglomerados empresariales globales, por ejemplo, DirecTV es parte de AT\&T y su conglomerado recientemente adquirido Time Warner Inc.
Ahora bien, siendo este el tema objeto de análisis en este capítulo, es trascendental comprender que en la actualidad se presenta una disrupción en el mercado audiovisual, de radio y de música, por la entrada y fuerte crecimiento de nuevos proveedores de contenido audiovisual basados en internet (OTT). Lo anterior genera que este mercado se encuentre aún más dinamizado, pues los operadores basados en Internet ejercen una presión competitiva importante, que cambia las dinámicas del mercado, como se desarrollará a continuación.

Así, los servicios OTT han permitido la difusión del consumo de contenido, mercados audiovisuales globales, una mayor posibilidad de elección y nuevas oportunidades para los creadores de contenido (Comisión de Regulación de Comunicaciones, 2019, p. 30).

\section{A. Sobre la competencia ejercida por operado- res basados en Internet}

En secciones precedentes se puso de relieve cómo los cambios tecnológicos están impactando la dinámica del mercado minorista de contenidos audiovisuales, particularmente el mercado minorista de contenidos de televisión. Los avances en tecnologías de transmisión como el streaming, que requieren menor ancho de banda y se prestan a precios asequibles, y la creciente apropiación de teléfonos inteligentes, ha permitido que servicios de suscripción de video bajo demanda (SVOD) (v.gr. Netflix, Amazon, YouTube, Twitter, Claro Video, Movistar Play), transmisión de video bajo demanda (TVOD) (v.gr. Apple) y otros OTT, compitan con mayor eficacia y resultados con los servicios tradicionales de TV.

Efectivamente, los operadores OTT, varios con un músculo financiero superior a los operadores tradicionales, ofrecen un catálogo (y competencia) sin precedentes en cuanto a opciones audiovisuales. En respuesta, los operadores lineales tradicionales, como los FTA - con las plataformas en línea de Caracol y RCN en Colombia, la plataforma BBC iPlayer en Reino Unido, o MyTF1 en Francia-, y los operadores de televisión por suscripción - como HBO GO, DirecTV Play, Claro Video, WinSport, Movistar Play, etc. - han desarrollado servicios y aplicaciones a pedido para usar en computadoras, Smart TV, dispositivos móviles y tabletas, que aumentan sus servicios de transmisión y compiten con los servicios puros (OTT), como los que brindan Facebook, Netflix, Amazon, Apple y Google.

Por ejemplo, los operadores FTA ofrecen sitios web y aplicaciones de transmisión en línea gratuitos, abiertos a cualquier usuario de Internet. Los consumidores pueden usar estos sitios y aplicaciones 
para ver el contenido de cada operador en el sitio relevante, en vivo o de manera diferida (servicio de catch-up), pues las principales redes FTA generalmente cargan su contenido en sus plataformas poco después de su emisión. Por su parte, los operadores de televisión restringida generalmente limitan sus plataformas de transmisión por Internet a sus propios usuarios, como es el caso de DirecTV Play, Claro Video, etc.

En los últimos años, tanto a nivel académico como a nivel regulatorio, en decisiones de las agencias de competencia (particularmente en el ámbito del ejercicio del control ex ante de concentraciones empresariales) y en estudios de mercado desarrollados o comisionados por reguladores sectoriales como la CRC colombiana, el IFT mexicano y la Oficina de Comunicaciones del Reino Unido (OFCOM), se ha debatido sobre la adecuada definición de los mercados relevantes en la industria de contenidos audiovisuales. En particular, se ha analizado si los servicios de video bajo demanda OTT deberían considerarse complementos o sustitutos ${ }^{16}$ de la televisión tradicional (abierta o por suscripción).

Las posiciones no han sido unánimes. En el más reciente estudio del mercado de servicios OTT elaborado por la CRC, la autoridad no encontró evidencia significativa que apuntara hacia un fenómeno de cord-cutting por parte de los usuarios de los servicios de televisión por suscripción (i.e. cuando éstos deciden cancelar sus planes y únicamente consumir contenidos VoD), y, además, encontró que las categorías de contenido consumidas por los usuarios varían entre la televisión por suscripción y los servicios $\mathrm{OTT}^{17}$. Todo ello, en su concepto, sugiere que entre los servicios OTT y la televisión por suscripción existe una relación de complementariedad (Comisión de Regulación de Comunicaciones, 2020, pp. 33-37). Dicha relación se ve más claramente en lo que atañe a los servicios de VoD pagos (principalmente, por suscripción, siendo Netflix el jugador más importante en el contexto colombiano), en particular, en lo relacionado a canales premium de televisión por suscripción (Comisión de Regulación de Comunicaciones, 2020, p. 39) ${ }^{18}$. En lo alusivo a la televisión abierta, la CRC destaca cómo no existe evidencia de una afectación al consumo de la televisión pública ante la mayor demanda por servicios OTT de VoD e incluso, destaca cómo la televisión digital terrestre (en adelante, TDT), aumentó en términos de cobertura entre 2018 y 2019 (Comisión de Regulación de Comunicaciones, 2020, p. 61).

En atención a lo anterior, cabe advertir que la CRC no descarta una posible existencia de sustituibilidad entre los servicios antedichos, pues, pese a no existir, en su concepto, competencia basada en el precio entre los mismos, sí reconoce que rivalizan por la atención de las audiencias (el tiempo de la gente) (Comisión de Regulación de Comunicaciones, 2020, p. 61$)^{19}$. Lo anterior hace factible que las plataformas OTT ejerzan presiones competitivas sobre los servicios de televisión tradicionales en mercados conexos, tales como el mercado de pauta publicitaria (Slaughter and May, 2018), que según se vio en acápites precedentes de este documento, ha sido reconocido por las autoridades de competencia y la literatura económica como un

16 Los complementos son productos que son consumidos de manera conjunta por los consumidores, de manera que la demanda por ambos productos se ve afectada de una misma manera por variaciones en el precio de cualquiera de ellos (i.e. si el precio de uno disminuye, incrementa la demanda por ambos productos, y si el precio de alguno aumenta, sucede lo propio con la demanda por ambos productos). Los productos sustitutos son aquellos que son considerados intercambiables por los consumidores, en atención a sus características, sus precios y su supuesto uso. Ante fluctuaciones en el precio de cualquiera de los productos sustitutos, la demanda por el otro se ve afectada a través de una relación inversa; es decir, si disminuye el precio de uno de los productos, la demanda por el otro se reduce, mientras que, si el precio de uno de los productos se eleva, la demanda por el sustituto incrementa.

17 La CRC identificó que el contenido más consumido a través de la televisión digital terrestre (abierta) son las novelas, seguido por las noticias. Tratándose de la televisión por suscripción, los contenidos más consumidores son noticias, seguidos por realities. A su turno, en las plataformas AVOD, los musicales tienen mayor preeminencia entre el público colombiano, mientras que en las plataformas PVOD, las series prevalecen (Comisión de Regulación de Comunicaciones, 2020, p. 34).

18 En el acápite de conclusiones, el informe expresa:

En lo que respecta a los servicios audiovisuales, la estimación de los modelos econométricos de aquellos que se prestan en línea demostró que un hogar que use OTT de video tiene una mayor probabilidad de suscribirse a TV por suscripción, sugiriendo una eventual complementariedad entre estos dos servicios, sin embargo, no es contundente la relación entre los OTT de video pagos y la TV por suscripción (nivel de significancia al 10\% y coeficiente muy bajo). Los hogares que usen OTT de video y OTT de video pagos tienen una mayor probabilidad de suscribirse a TV por suscripción premium, principalmente, en los estratos 4, 5 y 6 (Comisión de Regulación de Comunicaciones, 2020, p. 61).

19 Un estudio realizado por Slaughter and May (2018) resalta cómo, al menos en el contexto europeo, es común que los usuarios intercalen su consumo de contenidos audiovisuales entre diferentes tipos de plataformas, lo que incluye servicios de televisión abierta, televisión por suscripción y servicios de VoD o SVOD. Así,

cada uno de estos servicios competirá por la atención del usuario (que también significa competir por el contenido más atractivo para atraer al usuario). El bloqueo de los consumidores [lock-in] claramente no es un inconveniente cuando los consumidores consumen contenidos en múltiples plataformas [multi-home] en este grado (traducción libre de los autores; corchetes y resaltado fuera del texto) (Slaughter \& May, 2018, p. 9) [traducción libre] [el énfasis es nuestro] 
mercado en el que efectivamente compiten medios de comunicación tradicionales como revistas y sitios web de noticias, canales de televisión, redes sociales, juegos y otras aplicaciones móviles, entre otros. En el entorno de plataformas audiovisuales, cabe advertir que la competencia por la atención de las audiencias puede resultar particularmente intensa tratándose de los servicios financiados por publicidad (como el AVOD), en los cuales se ha considerado que, si bien los usuarios no pagan un valor monetario por acceder al contenido, sí pagan en cierta medida con su atención y con la información personal que entregan a la plataforma ${ }^{20}$.

En línea similar a la adoptada por la CRC, la Fiscalía Nacional Económica de Chile (en adelante, FNE), en su evaluación de la reciente integración entre The Walt Disney Company y Twenty-First Century Fox, aseveró que las plataformas OTT no compiten con la televisión de pago, comoquiera que ambos servicios responden a diferentes preferencias de los consumidores. En consecuencia, en opinión de la autoridad de competencia chilena, se trata de productos complementarios (Informe de aprobación, Rol de causa FNE F155-2018, 2019, párrs. 26-27). Adicionalmente, destaca cómo el mercado de video bajo demanda OTT se encuentra menos desarrollado de lo que sucede en otros países, mencionando como ejemplo a Estados Unidos, lo que resulta de especial relevancia tratándose de eventos en vivo (Informe de aprobación, Rol de causa FNE F155-2018, 2019, párr. 27). Puntualiza la autoridad que, en tales casos:

[...] las plataformas OTT se enfrentan a un desafío adicional, ya que no se trata de almacenar contenidos para ser visualizados en tiempos diferidos, sino que se requiere de la capacidad necesaria para exhibir programación en tiempo real, que será visualizado por una audiencia relevante en simultáneo. Ello requiere de un desarrollo tecnológico adicional, capaz de evitar que el aumento en tráfico para una misma plataforma genere disminuciones en la calidad de la transmisión, o incluso apagones por la existencia de un tráfico excedido (Informe de aprobación, Rol de causa FNE F155-2018, 2019, párr. 27).

En concordancia con el razonamiento anterior, el IFT, en algunas decisiones de control previo de integraciones, ha argumentado que los servicios OTT no podrían ser considerados sustitutos de los servicios de televisión y audio restringido (en adelante, STAR). En concreto, en el análisis de la concentración entre AT\&T y Time Warner, el regulador mexicano señaló que, aun cuando mediaban similitudes entre los servicios OTT y de STAR, en ese momento (mediados de 2017) no podía predicarse la existencia de sustituibilidad alguna en atención a dos factores: (i) su disponibilidad y (ii) los costos de acceso para los usuarios finales (Acuerdo P/IFT/150817/487, 2017, p. 76). Así, dado que para acceder a los servicios OTT es indispensable pagar por una conexión a Internet de banda ancha y que el nivel de penetración de banda ancha en el país era bajo y asimétrico (a nivel geográfico) para ese entonces, no toda la población tenía la posibilidad de acceder a los servicios OTT y de STAR en simultáneo, descartándose así cualquier posibilidad de sustitución (Acuerdo P/ IFT/150817/487, 2017, p. 76).

Sin embargo, en años recientes, se puede apreciar una postura más ponderada por parte del IFT. En su documento "Visión regulatoria de las telecomunicaciones y la radiodifusión 2019-2023", al abordar la temática de los servicios OTT, no descarta que los mismos puedan llegar a constituir sustitutos de los servicios tradicionales de telecomunicaciones y de contenido audiovisual (Instituto Federal de Telecomunicaciones, 2018, pp. 32-33). Para la entidad, resulta pertinente examinar las implicaciones del crecimiento de los servicios OTT en los mercados de telecomunicaciones y radiodifusión,

Texto original:

A typical viewer will multi-home and switch consumption regularly between different providers. In Europe many consumers will (i) watch free TV; (ii) watch Pay TV; and (iii) use more than one VOD or SVOD service (in the UK and Germany the average VOD household now subscribes to two VOD services), including by renting out content via socalled 'transactional VOD'. Each of these services will be competing for the viewer's attention (which also means competing for the most attractive content to attract the viewer). Consumer lock-in is clearly not an issue where consumers multi-home to this degree.

20 Esta idea se ve reflejada el estudio de la Competition and Markets Authority del Reino Unido, el cual asevera que [a]unque los consumidores no pagan dinero por estos servicios [gratuitos], se puede considerar que pagan por ellos al entregar a la plataforma su atención e información sobre ellos mismos. Las plataformas financiadas por medio de publicidad pueden combinar la atención de sus usuarios con información contextual o personal que tengan sobre ellos para entregar anuncios muy específicos, que son altamente demandados por los anunciantes $(2019$, p. 36) [traducción libre]

Texto original:

Although consumers do not pay money for these services, they can be considered to pay for them by giving the platform their attention and data about themselves. Advertising-funded platforms are able to combine the attention of their users with contextual or personal information they have about them to serve highly-targeted adverts, which are in high demand by advertisers.

Al respecto, también véase Cabrera Blázquez et al. (2016, pp. 19-23). 
y la posibilidad de que tales servicios representen complementos o sustitutos de los productos ofrecidos en los segundos, máxime si se considera el aumento en la cantidad y la calidad de las conexiones de Internet de banda ancha fija y móvil, condición necesaria para la creciente adopción y apropiación de servicios de OTT de VoD (Instituto Federal de Telecomunicaciones, 2018, pp. 32-33) $)^{21}$. A su turno, en el "Estudio sobre el mercado de contenidos audiovisuales y relaciones verticales en la industria de telecomunicaciones" (2018), se resalta lo siguiente:

Dada la dinámica de crecimiento que muestran los servicios de Video OTT, el análisis de sustituibilidad debe hacerse con un enfoque prospectivo tomando en cuenta la evolución esperada del mercado, con énfasis en el estudio de las barreras que puedan enfrentar los servicios SVOD para competir con la TV de paga. El crecimiento observado de estos servicios en México muestra una tendencia a la reducción y posible eliminación de estas barreras, lo cual impondrá una presión competitiva creciente sobre los proveedores de TV (SAI Derecho y Economía, 2018, párr. 464) [el énfasis es nuestro].

Ahora bien, en el contexto de la Unión Europea y Estados Unidos, han existido posiciones disímiles en relación con esta temática. En el ámbito europeo, un estudio preparado para la Comisión Europea, publicado en 2014, establece que los servicios de video bajo demanda por suscripción (SVOD) pueden llegar a verse como complementos o sustitutos de la televisión por suscripción (European Audiovisual Observatory, 2014, p. 149). Sin embargo, recientemente, en su examen de la operación de integración entre The Walt Disney Company y Twenty-First Century Fox, la autoridad estimó que la distribución de contenido para entretenimiento en casa a través de medios físicos/convencionales constituía un mercado producto distinto a la distribución de contenido para entretenimiento en casa digital (Caso M.8785, The Walt Disney Company/Twenty-First Century Fox, 2018, párr. 50). Adicionalmente, en lo que atañe al mercado de licenciamiento de conte- nido audiovisual, advirtió cómo la segmentación en función del tipo de contenido y el medio de exhibición (exhibition window), continuaba siendo relevante para los productores, radiodifusores y distribuidores minoristas (Caso M.8785, The Walt Disney Company/Twenty-First Century Fox, 2018, párr. 69).

Cabe en todo caso mencionar que, tratándose del mercado de distribución minorista de contenido audiovisual, la Comisión no arribó a una conclusión definitiva en torno a la factibilidad de sustitución entre servicios OTT y servicios de televisión de pago, pero tampoco fue necesaria una evaluación más a fondo en tanto no hubiera afectado sus conclusiones respecto de la conformidad de la transacción con el ordenamiento de competencia regional (Caso M.8785, The Walt Disney Company/TwentyFirst Century Fox, 2018, párrs. 97-99). Ello no es óbice para compartir algunas de las apreciaciones realizadas por agentes de la industria encuestados en el curso del análisis de mercado. Así, se manifestó que los servicios de video bajo demanda por suscripción (SVOD) constituyen un complemento de paquetes de televisión por suscripción básicos, al paso que otro agente de mercado denotó que los jugadores OTT están adquiriendo un volumen de contenido significativo, por lo cual compiten directamente con su servicio premium de televisión por suscripción (Caso M.8785, The Walt Disney Company/Twenty-First Century Fox, 2018, párrs. 97-99).

Por último, se traerá a colación un caso bastante sonado en Estados Unidos, dada la integración vertical que se generó entre un Proveedor de Servicio de Internet -ISP, por sus siglas en inglés- y un productor y distribuidor de contenidos audiovisuales. Hacemos referencia a la integración entre AT\&T y Time Warner, la cual fue aprobada, sin condicionamientos, por la Corte del Distrito de Columbia en junio de 2018 (Estados Unidos c. AT\&T Inc., y otros, 2018). Dicha sentencia reconoce en forma expresa que los programadores y distribuidores locales se están enfrentando a una competencia acrecentada por parte de servicios OTT innovadores, que incluyen SVOD y MVPD ${ }^{22}$ virtuales, quienes se be-

21 Respecto de la relevancia que revisten la disponibilidad y calidad de los servicios de Internet de banda ancha en la actividad económica de las plataformas audiovisuales OTT, en la Resolución por virtud de la cual se aprueba la concentración entre AT\&T y Time Warner, expresa el IFT lo siguiente:

La gestión de los proveedores de servicios de Internet y la fijación de precios de los servicios de banda ancha pueden afectar a los distribuidores de programación de video en línea. En particular, los distribuidores de programación de video OTT podrían verse perjudicados competitivamente si los proveedores de servicios de Internet (ISP, por las siglas en inglés de Internet Service Provider) retrasaran o afectaran de la entrega del video que transita por sus redes (Acuerdo P/IFT/150817/487, 2017, p. 47).

Esta postura es reiterada en la reciente decisión de aprobación, bajo condiciones, de la integración entre The Walt Disney Company y Twenty-First Century Fox (Acuerdo P/IFT/110319/122, 2019, p. 51).

22 Distribuidores Programadores de video Multi-canal, o Multi-channe/ Video Progamming Distributors. Un MVPD virtual suministra múltiples canales de televisión a través de Internet sin proveer su propia infraestructura de transporte de datos, como cable coaxial, fibra óptica o tecnología satelital. Ejemplos de estos proveedores son DirecTV Now, YouTube TV y Hulu Live. Véase, Engelson (2018). 
nefician de la integración vertical que permite llevar a cabo la creación, agregación y distribución de contenido in-house (Estados Unidos c. AT\&T Inc., y otros, 2018, pp. 18-19).

Según el fallo, la integración vertical antedicha trae dos beneficios sustanciales para los proveedores de contenido audiovisual mediante OTT: (i) reduce la posibilidad de que surjan desacuerdos en la negociación para la adquisición de licencias y derechos sobre contenidos, entre distribuidores mayoristas/programadores y distribuidores minoristas (bargaining friction); y (ii) la distribución que se efectúa sobre Internet permite a los proveedores de SVOD acceder a datos valiosos sobre sus clientes (Estados Unidos c. AT\&T Inc., y otros, 2018, pp. 19-20). Este segundo aspecto deviene particularmente relevante, comoquiera que el acceso a los datos de visualización de los consumidores permite a las plataformas OTT (i) determinar qué tipo de contenidos tienen mayor popularidad, priorizando su inversión en generar más cantidad de dichos contenidos; (ii) incide en la efectividad de los esfuerzos de mercadeo frente a los consumidores, y permite a los proveedores hacer recomendaciones de contenido basadas en las preferencias que éstos han revelado según los contenidos visualizados previamente; (iii) permite a las plataformas enviar publicidad dirigida a los consumidores, lo que la hace más atractiva frente a anunciantes (Estados Unidos c. AT\&T Inc., y otros, 2018, pp. 19-20).

Asimismo, la sentencia denota cómo las presiones competitivas generadas por los prestadores de servicios de SVOD se trasladan al ámbito de la producción y la atracción de talento para la creación de contenidos como películas y series, lo que incrementa los costos enfrentados por productores de contenido audiovisual tradicionales (Estados Unidos c. AT\&T Inc., y otros, 2018 p. 23). Por lo demás, esta anotación también la destaca el estudio de Ampere Analysis (2019) sobre el mercado de VoD en Reino Unido, referenciado en varias secciones del presente artículo. Ampere Analysis sostiene que los jugadores internacionales consolidados en el mercado, como Netflix y Amazon Prime po- drán beneficiarse de economías de escala que les permitirá mejorar las ofertas de firmas locales o más pequeñas para la adquisición de talento, mercadeo, producción y adquisición de contenidos ${ }^{23}$.

Como contrapartida a la creciente innovación de las plataformas OTT, la providencia menciona la constante disminución de ingresos experimentada por proveedores de televisión por suscripción tradicionales, resaltando la creciente tendencia al cord-cutting y cord-shaving ${ }^{24}$ en Estados Unidos, en donde los usuarios de televisión de pago cancelan o recortan (respectivamente) sus suscripciones a favor de servicios prestados por OTT (Estados Unidos c. AT\&T Inc., y otros, 2018, p. 22). Muestra de este fenómeno es el creciente ofrecimiento de servicios virtuales de MVPD (lineales) o de VoD en sentido estricto por parte de los operadores de televisión por suscripción, como una alternativa para complementar su oferta convencional y atender la demanda ascendente por servicios audiovisuales que puedan verse en cualquier momento y lugar.

En vista de todo lo expuesto, el fallo colige que las plataformas de video OTT (y las SVOD en particular), compiten directamente con proveedores tradicionales de servicios de televisión por suscripción en la medida en que compiten por el tiempo (limitado) dedicado a entretenimiento de las personas (Estados Unidos c. AT\&T Inc., y otros, 2018 pp. 24-25), i.e. por su atención, según hemos planteado a lo largo del presente documento.

Pues bien, el análisis hasta aquí efectuado permite concluir que, la complementariedad o sustituibilidad de los servicios de video bajo demanda OTT pueden ser sustitutos de la televisión abierta o la televisión por suscripción $-y$, por tanto, competir directamente con estas-, dependiendo de las condiciones particulares del mercado de referencia que se esté analizando. Teniendo en cuenta que el acceso a un servicio de Internet de banda ancha de calidad es un prerrequisito para el disfrute de gran parte de los contenidos sobre los cuales rivalizan los operadores tradicionales de televisión (v.gr. películas, series, documentales y

23 Según señala el estudio de Ampere Analysis:

Se pueden llegar a acuerdos a nivel internacional, en todo el negocio: el contenido original se puede producir con una audiencia de decenas de millones de suscriptores; la distribución global puede ser prometida y apalancada en el marco de adquisiciones de contenido; y cientos de países pueden estar cubiertos cuando se logren acuerdos para licenciar aplicaciones a agregadores como fabricantes de Smart TVs o de dispositivos de streaming (2019, p. 14) [traducción libre].

Texto original:

Deals can be struck on an international basis, across the entire business: originals can be produced with an audience of tens of millions of subscribers; global distribution can be promised and leveraged in content acquisitions; and hundreds of countries can be covered when striking deals to license applications to aggregators such as Smart TV or streaming device manufacturers.

24 El fenómeno del cord-shaving alude a la reducción del gasto en las suscripciones de televisión a favor de los servicios audiovisuales en línea (Comisión de Regulación de Comunicaciones, 2020). 
otros contenidos factuales/culturales), siendo de especial importancia para la transmisión de eventos en vivo como eventos deportivos, será más probable que exista relación de sustitución en aquellos mercados en los que existan niveles altos de penetración de servicios de Internet de banda ancha, sin que existan amplias disparidades entre regiones (v.gr. ciudades capitales vs. sector rural).

Asimismo, deviene fundamental considerar el grado de penetración de dispositivos que soporten el consumo de los contenidos ofrecidos por plataformas OTT de VoD, como Smart TV, teléfonos móviles, computadores y dispositivos de streaming como el Apple TV y el Amazon Firestick. De lo contrario, difícilmente podría hablarse de una competencia efectiva por la atención y tiempo dedicado al entretenimiento de los consumidores, cuando una buena parte de la audiencia potencial no tiene posibilidad de acceder a un servicio de Internet de calidad, y a dispositivos que permitan conectarse al mismo, para disfrutar de los contenidos suministrados por las plataformas OTT.

Ahora bien, ello no es óbice para reconocer que los servicios de video bajo demanda OTT, cuando menos, actúan como complementos frente a los servicios de FTA y televisión por suscripción, pues permiten que los consumidores accedan a una gran diversidad de contenidos desde una multiplicidad de dispositivos, en cualquier lugar en que se encuentren, eliminando las limitaciones propias del modelo de televisión con programación y horarios predefinidos. En cierta medida, podría sostenerse que, en los mercados en los cuales estos servicios se erigen en complementos y no sustitutos de la televisión tradicional (o donde se presenta más el fenómeno de cord-shaving que el cord-cutting), ello obedece no sólo a las limitaciones en la penetración de Internet de banda ancha de calidad, sino a las ofertas comerciales de los operadores tradicionales (puntualmente, de los operadores de televisión por suscripción), los cuales suelen ofrecer descuentos sustanciales por la adquisición de servicios empaquetados de telefonía fija, Internet fijo y televisión, aplicando precios elevados a las ofertas que involucren en servicio de Internet exclusivamente ${ }^{25}$.

Como comentario final, cabe considerar que, bajo estas dinámicas competitivas, podrían emerger nuevas barreras a la entrada y permanencia de los agentes que concurren a estos mercados. Budzinski y Lindstädt-Dreusicke aseveran que, si bien la escasez de espectro electromagnético no constituye un obstáculo relevante de cara a los servicios de streaming (como sí es el caso para los proveedores tradicionales de televisión, v.gr. FTA), el acceso a una amplia gama de contenidos de calidad, que resulten atractivos para los consumidores, puede erigirse en una barrera de entrada en tanto dichos contenidos pueden verse limitados en su disponibilidad (v.gr. a raíz de cláusulas de exclusividad), o los precios de licenciamiento pueden resultar en exceso elevados para firmas que no cuenten con un músculo financiero significativo (2018, p. 28).

En este punto, es oportuno recordar el estudio de Ampere Analysis, según el cual, los servicios de video bajo demanda de alcance internacional (v.gr. Netflix, Amazon Prime, YouTube) podrían adquirir ventajas competitivas frente a plataformas VoD locales, puesto que, debido a su músculo financiero y posicionamiento en el mercado, podrían detentar mayor poder en las negociaciones para la adquisición de contenido en mercados aguas arriba, al paso que podrían ser preferidos por agrupadores de contenido (como fabricantes de Smart TV y otros dispositivos de streaming) dada su mayor influencia frente a los consumidores (2019, p. 14). Igualmente, el tamaño y el alcance global de plataformas OTT de VoD incrementaría el rango de audiencia al cual podrían acceder (lo que puede resultar de particular interés para proveedores enfocados en contenido de nicho, que carece de grandes audiencias potenciales), y permitiría a los proveedores OTT amortizar sus gastos en tecnología en un mercado más amplio (Ampere Analysis, 2019, p. 22).

Con todo, al tratarse de una industria que está en constante cambio, el análisis de dichas barreras (y la posibilidad que puedan tener de impedir una competencia efectiva en los mercados asociados a contenidos audiovisuales) deberá efectuarse caso por caso, teniendo en cuenta factores como la participación y poder de mercado de las empresas que concurren a los mercados relevantes, el poder de negociación de los productores y oferentes de contenido, las preferencias actuales de los consumidores y la estructura de costos (v.gr. si los costos hundidos son representativos).

\footnotetext{
Concluye la CRC:

[...] [E]l empaquetamiento al interior de los servicios que se prestan podría estar jugando un papel importante en la ausencia del fenómeno de cord-shaving. Más aún, el empaquetamiento entre servicios (voz y mensajes, o voz, mensajes y televisión, por ejemplo) podría explicar que no se presenta sustitución de servicios audiovisuales tradicionales por servicios a través de plataformas en línea, esto es, cord-cutting (Comisión de Regulación de Comunicaciones, 2020, p. 63).
} 


\section{B. Competencia en la industria de contenido audiovisual deportivo y la dinámica de los operadores OTT}

En recientes decisiones, distintas autoridades de competencia en ejercicio del control ex ante de concentraciones empresariales (destacándose el caso The Walt Disney Company-Twenty-First Century Fox), han analizado de manera detallada las condiciones de competencia en mercados asociados a contenidos deportivos, por tratarse de una categoría programática especial con impacto significativo en otros eslabones de la cadena de valor y mercados conexos como el de pauta publicitaria. En estos casos, asumen, de forma errada, que el contenido deportivo no compite con otros tipos de contenido. $Y$ el yerro consiste en que, al segmentar el contenido, por el tipo de contenido, no determinan de forma particular la capacidad que tiene cierto tipo de contenido de captar la atención de los demás tipos de contenido.

Así se refleja en la evaluación del Departamento de Justicia de los Estados Unidos, donde la principal preocupación frente a la integración fue precisamente que la misma combinaría dos de las cadenas de canales deportivos más importantes en ese mercado geográfico: la franquicia de ESPN, controlada por The Walt Disney Company, y veintidós cadenas regionales deportivas de propiedad de Twenty-First Century Fox (Estados Unidos c. The Walt Disney Company y Twenty-first Century Fox, 2018). El Departamento de Justicia destacó que la existencia de canales que ofrezcan contenido deportivo en vivo dentro de los paquetes ofrecidos a los consumidores finales es un factor determinante al momento de adquirir servicios de televisión por suscripción (Estados Unidos c. The Walt Disney Company y Twenty-First Century Fox, 2018, pp. 5-6).

Así pues, en concepto de la entidad, existía un riesgo de que, corolario del mayor poder de negociación que ostentaría The Walt Disney Company en la reventa de contenidos deportivos, en calidad de operador mayorista, se presentara un alza en el valor de las licencias para la transmisión -y retransmisión- de dichos contenidos adquiridas por distribuidores minoristas, lo que se trasladaría a los consumidores finales mediante precios más elevados para los servicios de televisión por sus- cripción. Lo anterior, comoquiera que, atendiendo al atractivo de determinados contenidos deporti$\operatorname{vos}^{26}$, la entidad integrada podría amenazar a los distribuidores minoristas con la eliminación simultánea de sus canales (ESPN más las RSN de Fox) de su parrilla de programación (blackout), haciendo que los últimos se vieran conminados a acceder a los términos contractuales de The Walt Disney Company para no perder su clientela (Estados Unidos c. The Walt Disney Company y Twenty-First Century Fox, 2018, p. 7).

Esto podría articularse con el precedente NCAA c. Board of Regents of the University of Oklahoma (1984), en el cual la Corte Suprema de los Estados Unidos estableció, respecto de los partidos de fútbol americano interuniversitario, que la emisión televisiva de los mismos, por resultar especialmente atractivos para los fanáticos del deporte, genera una audiencia única y singularmente llamativa para anunciantes publicitarios y para las cadenas de televisión, las últimas en su calidad de clientes de los titulares de los derechos sobre el contenido (usualmente, ligas y equipos de fútbol). Ello implica que las programaciones alternativas que se ofrezcan en televisión en la misma franja horaria no puedan, en la práctica, cautivar a una audiencia de igual magnitud. En este sentido, para las cadenas que realizan la emisión, y los anunciantes interesados en adquirir espacios publicitarios de dichas cadenas, no existen sustitutos efectivos frente a tales partidos. En consecuencia, los titulares de los derechos sobre el contenido deportivo detentan también un poder de mercado significativo que puede influenciar los precios cobrados a los consumidores finales por los servicios de televisión por suscripción, al igual que los precios cobrados a los anunciantes de pauta publicitaria por los operadores mayoristas de contenidos para televisión.

Bajo la misma línea, el análisis del IFT de México, denota cómo los contenidos audiovisuales deportivos, a diferencia de otro tipo de contenidos que, según se vio en la Sección II, no conforman mercados producto independientes dado el interés de los consumidores en acceder a una amplia gama de contenidos y canales, "[...] son no replicables y tienen un valor perenne. La versión de máximo valor ocurre cuando se transmiten de manera simultánea al evento a partir del cual se crea. Las

26 En el caso concreto, las veintidós RSNs de propiedad de Fox licenciaban derechos locales y regionales para la transmisión televisiva en vivo del $48 \%$ de equipos profesionales de los Estados Unidos en tres de las cuatro ligas deportivas principales del país: Major League Baseball (MLB), National Basketball Association (NBA) y National Hockey League (NHL). Específicamente, las RSNs de Fox controlaban los derechos de transmisión del $50 \%$ de los equipos de la MLB, del $57 \%$ de los equipos de la NBA, y el $39 \%$ de la NHL. Véase, Estados Unidos c. The Walt Disney Company y Twenty-first Century Fox (2018, p. 4).

27 Además de ingresos por publicidad elevados, en tanto la atención que captan estos contenidos es constante (y se mantiene incluso durante las inserciones publicitarias) 
transmisiones diferidas en temporalidad pierden valor significativamente" (Acuerdo P/IFT/ 110319/122, 2019, p. 88). Bajo esta perspectiva, los contenidos audiovisuales deportivos premium, debido a su potencialidad para atraer altos niveles de audiencia ${ }^{27}$, y a su atributo de escasez derivado de su no replicabilidad, generan una demanda estable que se ha traducido en un aumento significativo en la adquisición - y el precio- de derechos de transmisión para distintas ventanas de visualización (v.gr. televisión de pago, televisión abierta, OTT que ofrecen video bajo demanda) (Acuerdo P/IFT/110319/122, 2019, p. 88).

Finalmente, el análisis de la FNE también reconoce que, dada la importancia que los consumidores chilenos atribuyen a los contenidos deportivos (en especial, el fútbol en vivo), los canales que los transmiten ejercen una influencia trascendental en mercados descendentes, en concreto, en la contratación del servicio de televisión por suscripción (Informe de aprobación, Rol de causa FNE F155-2018, 2019, párr. 18). Empero, pese a que la transacción conllevaba la agregación de los canales deportivos de The Walt Disney Company y Twenty-First Century Fox y, de contera, un eventual incremento en el poder de negociación del agente integrado, la autoridad no impuso condicionamientos en este ámbito. Lo anterior, debido a que (i) en el mediano plazo, el mercado para la adquisición de derechos de transmisión era contestable, debido a que los derechos suelen asignarse por términos de tres a cinco años ${ }^{28}$; (ii) existían dificultades técnicas para implementar una orden de desinversión dado el alcance regional de algunos de los derechos de transmisión en dicho momento detentados por ambas compañías; y (iii) por último, en vista del "fuerte dinamismo existente en la industria de consumo audiovisual [...], que se evidencia en la introducción de nuevas tecnologías y nuevas formas de transmisión de contenido" (Informe de aprobación, Rol de causa FNE F155-2018, 2019, párrs. 122-123).

Efectivamente, en materia de contenido deportivo, la competencia producida por los operadores OTT es especialmente relevante. Los nuevos jugadores compiten activamente en la adquisición de derechos de transmisión para eventos deportivos, especialmente Facebook (UEFA Champions League $^{29}$ y Copa Libertadores de la Conmebol ${ }^{30}$ ),
IMG con su Serie A Pass (Liga italiana) ${ }^{31}$ y Amazon (Premier League $^{32}$ y juegos de la NFL). También cabe mencionar que las ligas deportivas están comenzando a lanzar sus propios servicios de transmisión, para entregar directamente el contenido a los consumidores finales, como la NBA (liga estadounidense de baloncesto), NFL (liga estadounidense de fútbol americano), MBL (liga estadounidense de béisbol), ATP (tenis profesional masculino) y Juegos Olímpicos. Incluso, algunos deportistas están firmando millonarios acuerdos con plataformas OTT para la transmisión de eventos deportivos en los que participan, como es el caso del boxeador Saúl Canelo Álvarez quien a finales de 2018 firmó con la plataforma DAZN un contrato por 365 millones de dólares ${ }^{33}$.

Un ejemplo importante por la intensa y creciente competencia en esta industria es el de Facebook: esta exitosa red social se está convirtiendo en un operador OTT y ya ha ganado derechos de transmisión para la Champions League, cuyos partidos transmite en directo y de manera gratuita. Asimismo, resulta relevante resaltar que Facebook ha expresado su deseo de seguir penetrando el mercado de contenido audiovisual deportivo con otros eventos de reconocimiento global y regional. Concretamente, en Latinoamérica, Facebook ha contratado al cofundador de Esporte Interativo de Brasil, Leonardo Cesar, para ser el Director de Contenido Deportivo para América Latina, lo cual demuestra su intención de penetrar directamente este mercado en la región, iniciando con la transmisión de la Copa Libertadores. No en vano esta red social ocupa el tercer lugar a nivel de audiencias de VoD en España, y el quinto en Francia y Estados Unidos (Ampere Analysis, 2019, p. 7), y con su transmisión de la Copa Libertadores, tiene el potencial de atraer mayor demanda de parte de consumidores latinoamericanos.

De tal forma, no hay que subestimar la cada vez mayor penetración de las plataformas basadas en Internet que desde hace varios años vienen compitiendo con mucha fuerza en el mercado audiovisual, quienes, además de estar transformado el mercado audiovisual a escala global, inciden directamente en su contestabilidad. Al final de cuentas, incluso en el escenario en que se pensara que la concentración de contenidos deportivos en un

\footnotetext{
28 La decisión de la Superintendencia de Industria y Comercio es consonante con esta tesis de contestabilidad del mercado. Véase, la Resolución 92709 de la Superintendencia de Industria y Comercio (2018, pp. 33-35).

29 Véase, EFE (2018).

30 Véase, Blanco (2018).

31 Véase, Portafolio (2018).

32 Véase, AP (2018).

33 Véase, Rodríguez, S. (2018b) y Corbella (2018).
} 
único agente reduce el bienestar del consumidor, esta apreciación desestima que los consumidores tienen múltiples formas de acceder a contenido, y que las productoras de este compiten particularmente por la atención de los consumidores independientemente del tipo de contenido (Evans, 2013 , p. 317). Si insistimos en que la atención es una cantidad limitada de tiempo de visualización (Budzinski \& Lindstädt-Dreusicke, 2018), en tanto el tiempo es limitado y el contenido audiovisual es básicamente ilimitado, los productores, independientemente del tipo de contenido, seguirán compitiendo por el tiempo que los consumidores asignan para prestar atención al mismo. No tener esa perspectiva en cuenta, hace de cualquier análisis de estos mercados, inocuo.

\section{CONCLUSIONES}

En la actualidad, es dable aseverar que cada vez más son las empresas que compiten por el tiempo que los consumidores dedican a prestar atención al contenido. Este enfoque hace que el alcance de la competencia en la economía cultural y creativa sea mucho más intenso, y que las definiciones convencionales de mercados relevantes de producto, que trazan líneas divisorias basadas en criterios como las tecnologías de transmisión, o los contenidos que comercializan, puedan resultar insuficientes para captar la realidad del entorno competitivo.

Bajo la misma perspectiva, una teoría del daño en la economía cultural y creativa no debe medirse principalmente en términos de precios, producción reducida u otros daños relacionados con el dinero, sino las posibles limitaciones del consumidor para acceder a una variedad de productos culturales a los que prestar atención, mediante prácticas como el cierre de mercados (v.gr. originadas en estrategias de blackout de contenidos relevantes), cláusulas de exclusividad anticompetitivas o ventas atadas, entre otras.

Dentro del ámbito de la economía naranja, es decir del sector de la economía que recoge aquellas actividades que tienen su origen en la creatividad y que genera riqueza a través de la explotación de la propiedad intelectual, este artículo se centra en la industria de contenidos audiovisuales. Como se ha visto, esta industria está caracterizada en la actualidad por su dinámica competitiva cambiante, en razón a que la tecnología está modificando la oferta y la demanda. Por el lado de la oferta, la digitalización ha reducido las barreras para la creación y distribución de contenido. Por el lado de la demanda, el cada vez más fácil acceso a Internet de banda ancha y las mejoras en la infraestructura tecnológica, han permitido una proliferación en las opciones de los consumidores.
De lo anterior se desprende que la producción de contenido es un negocio global altamente competido, en donde los agentes de mercado buscan desarrollar contenido que atraiga espectadores que se enfrentan a múltiples alternativas de visualización. Igualmente, debe decirse que se trata de una industria multinivel en la que múltiples participantes están activos en diversos eslabones de la cadena de valor y que, en la actualidad, está siendo desafiada por una ola de nuevos competidores; en efecto, el mercado está siendo influenciado por aplicaciones en línea y otras aplicaciones de medios digitales. Así, por ejemplo, a nivel de producción de contenido y de suministro de películas y series, entre otros contenidos audiovisuales, la dinámica competitiva se ha disparado en los últimos años debido a la Internet, a las nuevas tecnologías, y por ende a los hábitos cambiantes de los consumidores. Por lo anterior, se ha facilitado la entrada de nuevos competidores al mercado, incluyendo los servicios de Video Gratis Por Demanda, Video Transaccional por Demanda, Video por Suscripción por Demanda, entre otros.

La dinámica competitiva en la industria de contenidos audiovisuales y plataformas digitales antedicha tiene un impacto evidente en los productos ofrecidos. A raíz de la proliferación de servicios de transmisión de contenidos a través de Internet, de la evolución de los servicios por pedido y la visibilidad de alternativas para los consumidores, es posible sostener que cada vez es más común ver múltiples opciones disponibles una al lado de la otra, de hecho, en la misma plataforma (v.gr. Apple ofrece en su plataforma tanto la opción de compra, de alquiler o de simple reproducción del contenido). De tal suerte, tanto la dinámica competitiva como el aumento en los productos ofrecidos en la industria de contenidos audiovisuales y las plataformas digitales evidencian nuevamente, como se mencionó, que la competencia gira en torno a la atención de los consumidores.

En este contexto, este artículo ha explorado la definición de mercados relevantes que tradicionalmente han acogido los organismos reguladores y las autoridades de competencia, complementándola con la inclusión de servicios OTT de video bajo demanda como factibles sustitutos o, cuando menos, complementos de los servicios de televisión abierta y televisión por suscripción. De igual forma, se analizó una categoría particular de contenido (contenidos deportivos), con miras a demostrar, por un lado, su incidencia en la competitividad de la oferta de los operadores audiovisuales en mercados aguas abajo, y de otro, la intensa competencia que existe entre proveedores de televisión abierta, proveedores de televisión por suscripción y plataformas OTT para adquirir los derechos de 
transmisión y ofrecerlos en los mercados mayoristas y/o minoristas.

Al respecto, y en aras de establecer una definición de mercado producto más acertada con relación a los mercados de la economía naranja (y puntalmente, de la industria de contenidos audiovisuales), se colige que un factor determinante para la inclusión de los servicios OTT como sustitutos de los servicios tradicionales de televisión será el nivel de penetración de Internet de banda ancha de calidad en un país específico (o en una región dentro del mismo, en caso de que proceda una definición más estrecha del mercado geográfico), y de dispositivos que soporten el consumo de contenidos OTT, de suerte que los consumidores efectivamente puedan incluir, dentro de los servicios que compiten por su atención/tiempo dedicado al entretenimiento, a estos medios digitales. Estos dos factores, a su turno, estarán determinados por la asequibilidad de los servicios de acceso a Internet de alta velocidad y los dispositivos habilitados para transmitir contenidos audiovisuales OTT.

Además de este constreñimiento estructural, será importante tener en cuenta las preferencias - declaradas y reveladas - de los consumidores en un mercado geográfico dado, lo que incluye considerar los niveles de audiencia e ingresos percibidos por los proveedores tradicionales y los servicios OTT como indicador de relevancia de ambos servicios en la mente de los consumidores.

Por ejemplo, Estados Unidos ha sido reconocido como uno de los mercados en donde la sustituibilidad entre productos de televisión tradicional y servicios OTT, a raíz de fenómenos como el cordcutting y el cord-shaving, sumado a los altos niveles de penetración de la Internet de banda ancha y los dispositivos para visualizar contenidos OTT, puede ser más factible. Sin embargo, sobre la base de las proyecciones de eMarketer, citadas en el reciente estudio publicado por la CRC, es posible afirmar que, en las regiones de Asia-Pacífico (donde el uso de servicios OTT audiovisuales supera con creces los de las demás regiones) y América Latina, las cuales tienen mayores proyecciones de crecimiento entre 2019 y 2023 (Comisión de Regulación de Comunicaciones, 2020, p. 9), podrían llegar a encontrarse fenómenos de sustitución entre jugadores tradicionales y los OTT, siempre que las condiciones de penetración de Internet y dispositivos conectados estén dadas.

Por último, no debe olvidarse que, salvo por algunas excepciones puntuales relacionadas con la transmisión de eventos deportivos de interés nacional, en los mercados de distribución minorista de contenidos audiovisuales (en donde actúan proveedores FTA, de televisión paga y OTT), los consumidores buscan acceder a la mayor variedad posible de contenidos de calidad, por lo que no es dable establecer mercados producto diferenciados basados en el contenido ofrecido. Este principio sirve de fundamento para determinar definiciones más amplias de mercado, lo que facilita la inclusión de servicios OTT en el mismo, junto con una teoría del daño asociada a las limitaciones injustificadas que podrían tener los consumidores para acceder a dicha variedad de contenidos y ocupar así su atención.

\section{REFERENCIAS}

Ampere Analysis (2019). The UK VoD market. CUrrent status and future developments. Estudio comisionado por OFCOM. https://www.ofcom. org.uk/_data/assets/pdf_file/0026/149075/ ampere-analysis-current-status-future-development.pdf

AP (7 de junio de 2018). Amazon compra derechos para transmitir partidos de la Premier League. El Economista. https://www.eleconomista. com.mx/tecnologia/Amazon-compra-derechos-para-transmitir-partidos-de-la-PremierLeague--20180607-0042.html

Batura, O., Van Gorp, N., \& Larouche, P. (2015). Online Platforms and the EU Digital Single Market: $A$ response to the call for evidence by the House of Lords Internal Market Sub-Committee. e-Conomics.

Blanco, T. (5 de octubre de 2018). Desde el próximo año, Facebook transmitirá la Copa Libertadores. El Espectador. https://www.elespectador. com/deportes/futbol-internacional/desde-elproximo-ano-facebook-transmitira-la-copalibertadores/

BOP Consulting (2010). Guía práctica para mapear las industrias creativas. British Council. https://cerlalc.org/wp-content/uploads/publicaciones/olb/PUBLICACIONES_ODAI_Guiapractica-para-mapear-las-industrias-creativas_ v1_010110.pdf

Budzinski, O., \& Lindstädt-Dreusicke, N. (2018). The New Media Economics of Video-on-Demand Markets: Lessons for Competition Policy. IImenau Economics Discussion Papers, 24(116). https://ssrn.com/abstract=3276036

Buitrago Restrepo, F. \& Duque Márquez, I. (2013). La economía naranja: Una oportunidad infinita. Banco Interamericano de Desarrollo. 
Cabrera Blázquez F.J., Cappello M., Grece C., \& Valais S. (2016). VOD, platforms and OTT: which promotion obligations for European works? IRIS Plus, European Audiovisual Observatory. https://rm.coe.int/1680783489

Comisión de Regulación de Comunicaciones (2015). Mercados audiovisuales en un entorno convergente.

(2016). Análisis de Mercados Audiovisuales en un Entorno Convergente. https://www.crcom. gov.co/recursos_user/2016/Actividades_regulatorias/analisis_mercados_audiov/160401_ Documento_Amarillo.pdf

(2019). El rol de los servicios OTT en el sector de las comunicaciones en Colombia. https://www. crcom.gov.co/uploads/images/files/ESTUDIOOTT-COLOMBIA.pdf

(2020). El rol de los servicios OTT en el sector de las comunicaciones en Colombia - Año 2019. https://www.crcom.gov.co/uploads/images/ files/CRC-EstudioOTT-2020-publicar-vf.pdf

Competition and Markets Authority (2019). Online platforms and digital advertising. Market study interimreport. https://assets.publishing.service. gov.uk/media/5dfa0580ed915d0933009761/ Interim_report.pdf

Conseil supérieur de l'audiovisuel (2016). Platforms and Access to Audiovisual Content. Competitive and Regulatory Issues. https://www.csa. $\mathrm{fr} /$ content/download/223681/597949/version/7/file/Platforms\%20and\%20access\%20 to\%20audiovisual\%20content.pdf

Corbella (18 de octubre de 2018). Canelo Álvarez firma el contrato más alto de la historia del deporte: 365 millones. Marca. https://www. marca.com/buzz/2018/10/17/5bc6e31ae5fde ae37f8b46b2.html

Departamento Nacional de Planeación (2016). El futuro del sector audiovisual en Colombia: Necesidad de política pública y reformas normativas en el marco de la convergencia tecnológica y las tendencias del mercado. https:// colaboracion.dnp.gov.co/CDT/Prensa/Publicaciones/Informe\%20convergencia\%20dyd\%20 rev_STEL\%2018-01-2017CEVC.pdf

EFE (16 de agosto de 2018). Facebook transmitirá gratis la Champions League. El Espectador. https://www.elespectador.com/deportes/futbol-internacional/facebook-transmitira-gratisla-champions-league/
Engleson, S. (14 de agosto de 2018). When Linear TV and Digital Collide: The Rise of the Virtual MVPD. Comscore. https://www.comscore. com/Insights/Blog/When-Linear-TV-and-Digital-Collide-The-Rise-of-the-Virtual-MVPD

European Audiovisual Observatory (2014). Ondemand audiovisual markets in the European Union (Reporte SMART 2012/0028). https:// doi.org/10.2759/51823

Evans, D. S. (2013). Attention rivalry among online platforms. Journal of Competition Law and Economics, 9(2), 313-358.

Falkinger, J. (noviembre 2003). Attention Economies (CESifo Working Paper Series No. 1079). https://ssrn.com/abstract $=466580$

Farrell, J., \& Klemperer, P. (2007). Coordination and Lock-In: Competition with Switching Costs and Network Effects. En Armstrong, M. \& Porter, R. (Eds.), Handbook of Industrial Organization, (Vol. 3., pp. 1970-2072). Elsevier B.V. http:// doi.org/10.1016/S1573-448X(06)03031-7

Festré, A., \& Garrouste, P. (2015). The 'Economics of Attention': A History of Economic Thought Perspective. CEconomia, 5(1), 3-36. https://doi. org/10.4000/oeconomia.1139.

Goldfarb, A., \& Tucker, C. (2011). Substitution Between Offline and Online Advertising Markets. Journal of Competition Law and Economics, 7(1), 37-44. https://doi.org/10.1093/joclec/ nhq034

Hotelling, H. (1938). The general welfare in relation to problems of taxation and of railway and utility rates. Econometrica, 6(3), 242-269. https://doi.org/10.2307/1907054.

Instituto Federal de Telecomunicaciones (2018). Visión regulatoria de las telecomunicaciones y la radiodifusión 2019-2023. http://www.ift. org.mx/sites/default/files/contenidogeneral/ transparencia/1vision19-23.pdf

Izquierdo Castillo, J. (2007). Distribución y exhibición cinematográficas en España. Un estudio de situación del negocio en la transición tecnológica digital (Tesis doctoral). Universitat Jaume I, Valencia, España.

Morales Montejo, C. (2014). El emprendedor de organizaciones innovadoras. Siglo del Hombre Editores.

Oxford Economics (2014). The economic impact of the creative industries in the Americas. https:// 
publications.iadb.org/en/publication/12503/ economic-impact-creative-industries-americas

Portafolio (17 de agosto de 2018). Plataforma de streaming transmitirá en Colombia la Liga italiana. Portafolio. https://www.portafolio.co/ tendencias/entretenimiento/plataforma-destreaming-transmitira-en-colombia-la-liga-italiana-520186

Ratliff, J. D., \& Rubinfield, D. L. (2010). Online Advertising: Defining Relevant Markets. Journal of Competition Law and Economics, 6(3). https:// doi.org/10.1093/joclec/nhq011

Rodríguez. A. (2018a, 12 de junio). The internet is finally going to be bigger than TV worldwide. Quartz. https://qz.com/1303375/internetusage-will-finally-surpass-tv-in-2019-zenithpredicts/

Rodríguez, S. (2018b, 17 de octubre). Canelo Álvarez firma espectacular contrato con DAZN por 365 millones de dólares. ESPN Digital. https://www.espn.com.co/boxeo/nota/_/ id/4875971/canelo-alvarez-firma-espectacular-contrato-con-dazn-por-365-millones-dedolares

Russo (15 de agosto de 2019). Brasil: OTT gana terreno mientras TV paga pierde fuerza. Prensario Internacional. https://prensario. tv/novedades/4362-brasil-ott-gana-terrenomientras-tv-paga-pierde-fuerza

SAI Derecho y Economía (2018). Estudio sobre el mercado de contenidos audiovisuales y relaciones verticales en la industria de telecomunicaciones. http://www.ift.org.mx/sites/default/ files/contenidogeneral/autoridad-investigadora/estudioversioncompletafinal-3.pdf

Sartor, P. (2016) La economía digital. Revista de Negocios del IEEM, (2), 22-26.

Semana (5 de octubre de 2016). Los colombianos prefieren Netflix y Youtube sobre la TV abierta. Semana. https://www.semana. com/tecnologia/articulo/los-colombianosprefieren-netflix-y-youtube-sobre-la-tvtradicional/473071/\#: :text=De\%20acuerdo\%20con\%20su\%20estudio,televidentes\%20 que $\% 2010$ \%20canales\%20tradicionales.

Shier, G. (2018). It's what you know about who you know: market power in digital platforms. Oxera Agenda December 2018. https://www.oxera. com/agenda/its-what-you-know-about-whoyou-know-market-power-in-digital-platforms/
Slaughter and May (2018). Securing the Benefits of the Digital Economy for European Consumers - A Case Study. https://ec.europa.eu/competition/information/digitisation_2018/contributions/slaughter_and_may.pdf

Teixeira, T. (2014). The Rising Cost of Consumer Attention: Why You Should Care, and What You Can Do about It (Working Paper 14-055). Harvard Business School. https://www.hbs.edu/faculty/Publication\%20Files/14-055_2ef21e7e7529-4864-b0f0-c64e4169e17f.pdf

Ulin, J. C. (2014). The Business of Media Distribution. Monetizing Film, TV, and Video Content in an Online World (2da ed.). Focal Press Taylor and Francis Group.

Valens, A. (19 de octubre de 2017). Report shows Twitch audience bigger than HBO's and Netflix. Gamepur. https://dotesports.com/the-op/ news/twitch-audience-hbo-netflix-18122

Waldfogel, J. (2018). Digital Renaissance: What Data and Economics Tell Us about the Future of Popular Culture (English Edition). Princeton University Press. Kindle file.

Wu, T. (2017). Blind Spot: The Attention Economy and the Law. Antitrust Law Journal, 82(3). https://doi.org/10.2139/ssrn.2941094

\section{LEGISLACIÓN, JURISPRUDENCIA Y OTROS DOCU- MENTOS LEGALES}

Caso M.1219, Seagram/Polygram, 1998 EUR-Lex CELEX LEXIS 31998M1219 (29 Sept. 1998) (UE).

Caso M.2050, Vivendi/Canal+/Seagram, 2000 EURLex CELEX LEXIS 32000M2050 (13 Oct. 2000) (UE).

Caso M.8785, The Walt Disney Company/TwentyFirst Century Fox, 2018 EUR-Lex CELEX LEXIS 32018M8785 (06 Nov. 2018) (UE).

Directiva 2018/1808 del Parlamento Europeo y del Consejo, de 14 de noviembre de 2018, por la que se modifica la Directiva 2010/13/UE sobre la coordinación de determinadas disposiciones legales, reglamentarias y administrativas de los Estados miembros relativas a la prestación de servicios de comunicación audiovisual (Directiva de servicios de comunicación audiovisual), habida cuenta de la evolución de las realidades del mercado, 2018 O.J. (L 303) (EU).

Estados Unidos c. AT\&T Inc. et al., 310 F. Supp. 3d 161 (D.D.C. 2018). 
Estados Unidos c. The Walt Disney Company and Twenty-First Century Fox, 83 FR 40553, Competitive Impact Statement submitted by the Department of Justice. (S.D.N.Y. 2018).

Fiscalía Nacional Económica, 19 de marzo de 2019, Informe de aprobación, Rol de la causa: FNE F155-2018 (Chile).

Instituto Federal de Telecomunicaciones, 11 de marzo de 2019, Acuerdo P/IFT/110319/122, Resolución mediante la cual el Pleno del Instituto Federal de Telecomunicaciones resuelve la concentración radicada bajo el expediente UCE/CNC-001-2018, notificada por The Walt Disney Company y Twenty-First Century Fox, Inc., Expediente UCE/CNC-001-2018 (Mex.).

Instituto Federal de Telecomunicaciones, 15 de agosto de 2017, Acuerdo P/IFT/150817/487, Resolución mediante la cual el Pleno del Instituto Federal de Telecomunicaciones autoriza llevar a cabo la concentración radicada bajo el expediente UCE/CNC-004-D16, notificada por AT\&T Inc., West Merger Sub Inc. y Time Warner Inc. sujeta al cumplimiento de condiciones, Expediente UCE/CNC-004-D16 (Mex.).
NCAA v. Board of Regents of the University of Oklahoma, 468 U.S. 85 (1984).

Ley 182 de 1995, 20 de enero de 1995, 41.681 Diario Oficial [D.O.] (Colom.).

Superintendencia de Industria y Comercio, 19 de abril de 2010, Resolución 20065, Radicación 09-122453 (Colom.).

Superintendencia de Industria y Comercio, 21 de diciembre de 2018, Resolución 92709, Radicación 18-201153 (Colom.).

Superintendencia de Industria y Comercio, 15 de febrero de 2017, Estudio Económico, Radicación 17-38927 (Colom.).

Superintendencia de Industria y Comercio, 17 de diciembre de 2012, Radicación 12-226871 (Colom.).

Superintendencia de Industria y Comercio, 21 de junio de 2017, Radicación 17-192278 (Colom.).

Superintendencia de Industria y Comercio, 31 de octubre de 2016, Radiación 16-335436 (Colom.). 